ISSN 00156043

\title{
ESTUDIOS
}

\section{Nuevos argumentos y políticas públicas para las zonas rurales latinoamericanas: una visión crítica'}

\section{Mateo Ambrosio Albalá2}

Palabras clave: Latinoamérica, desarrollo rural, zonas rurales, políticas públicas.

Key words: Latin-American, rural development, rural areas, public policies.

\section{Introducción}

Apenas se discute que la imagen tradicional asociada a las zonas rurales como 'agricultura', 'campo' y 'atraso' ha cambiado de forma considerable. En Andalucía hemos asistido durante las dos últimas décadas a este cambio de percepción sobre las zonas rurales (Moscoso, 2005; GARRIDO et al., 2006). La estrecha vinculación de las sociedades rurales con la actividad agrícola y con el medio natural sesgó

\footnotetext{
1 El presente artículo es un extracto de la tesis doctoral "Elementos institucionales en las zonas rurales: una propuesta metodológica para su identificación y valoración en comarcas de Andalucía y Nicaragua" elaborada por el autor y codirigida por los profesores Dr. Francisco Amador Hidalgo y Dr. José Juan Romero Rodríguez. La tesis se presentó en el Departamento de Gestión Empresarial y Métodos Cuantitativos de la Universidad de Córdoba y fue defendida en junio de 2007. Agradezco las valoraciones a una versión preliminar de mis codirectores de tesis, del Prof. Dr. Vicente González (Fundación ETEA para el Desarrollo y la Cooperación), de la Prof. Dra. $M^{a}$ Mar Delgado (Universidad de Córdoba) y del Dr. Luis Llambí (Instituto Venezolano de Investigaciones Científicas), así como los comentarios hechos por un evaluador anónimo y por miembros del Consejo de Redacción de la Revista de Fomento Social. Los errores y omisiones son de mi entera responsabilidad.

${ }^{2}$ Colaborador de la Fundación ETEA. Investigador invitado en la Universidad de Amberes. mateoambrosio@ya.com
} 
nuestra visión sobre estas áreas, posicionando al sector agrario en el centro de cualquier intervención pública. Sin perder este peso, progresivamente, en la acción pública se han ido incorporando nuevas cuestiones relacionadas con la calidad de las interrelaciones en el tejido socioinstitucional, y con una percepción ampliada de los activos y capacidades al alcance de la población rural. El aumento de las interrelaciones entre las ciudades y las áreas rurales han alterado nuestras percepciones mutuas, las demandas sociales se han modificado y, por ende, la actuación pública.

Cambios similares se observan en algunos países latinoamericanos. Durante las dos últimas décadas, la liberalización comercial y financiera y la reforma de la administración pública han tenido un impacto notable en las zonas rurales latinoamericanas. La liberalización comercial ha permitido la introducción de nuevas tecnologías y nuevos estándares de calidad, pero también la entrada de productos externos fuertemente subsidiados que han impactado en la agricultura de consumo interno y en la seguridad alimentaria. Junto a estos, otros factores evidencian las dificultades para impulsar procesos de cambio en las zonas rurales latinoamericanas. La escasez de garantías reales, consecuencia en gran medida de una propiedad rústica muy concentrada, continúa restringiendo el acceso a fuentes de financiación y la inversión. A ello hay que unir la escasa credibilidad de las garantías jurídicas, la inseguridad legal y las asimetrías en el acceso a información, conformando unos mercados locales imperfectos. En términos institucionales, la reforma de la administración pública se ha traducido en un desmantelamiento de la institucionalidad agraria. En otros ámbitos, las privatizaciones aceleradas en la gestión de suministros básicos (energía, agua, saneamiento) han debilitado aún más la prestación de servicios públicos y la precariedad en el acceso para un porcentaje importante de la población. Los procesos de descentralización político-administrativa son aún muy incipientes y el impulso a espacios de participación ciudadana amenaza con profundizar aún más las desigualdades locales.

Todos estos aspectos transcienden los límites de la actividad agraria y añaden nuevos elementos a considerar en el impulso a una transformación productiva e institucional en las zonas rurales. Esta visión ampliada de las zonas rurales está surgiendo de interpretaciones latinoamericanas autóctonas y se está asentando en las estrategias de intervención de organismos públicos y agencias de cooperación.

Con el presente artículo nos proponemos indagar en la emergencia de estos nuevos argumentos de política pública para intervenir en las zonas rurales latinoamericanas e identificar qué obstáculos persisten para su aplicación efectiva. 
El artículo está dividido en cuatro partes. En la primera repasaremos las principales líneas argumentales del 'desarrollo rural' en las cinco últimas décadas, propondremos una síntesis de los principales argumentos del 'enfoque renovado del desarrollo rural' e identificaremos organismos que, amparados en este nuevo enfoque, están impulsando nuevas propuestas de políticas rurales. A continuación exploraremos los primeros pasos hacia la construcción de una perspectiva latinoamericana del principio de 'cohesión social' y nos detendremos en caracterizar las tres principales construcciones latinoamericanas de propuestas ruralistas, señalando algunas experiencias de intervención que incorporan elementos del nuevo enfoque. En el apartado siguiente identificaremos algunas limitantes y obstáculos a la implementación de una política regional latinoamericana, a la luz de las condiciones institucionales y estructurales existentes, y expondremos una valoración crítica de las propuestas ruralistas expuestas. Concluiremos con unas reflexiones adicionales en las que proponemos algunos temas clave a considerar de cara a una transposición efectiva de estos nuevos argumentos en políticas públicas ${ }^{3}$.

Los paralelismos con la experiencia en Unión Europea serán inevitables y deudores, en nuestra opinión, del impacto de la experiencia europea en la reelaboración de estas propuestas latinoamericanas.

\section{Una visión renovada de las zonas rurales}

\section{I. Evolución de los principales argumentos del desarrollo rural}

Con una somera revisión podemos observar la sustancial evolución en los argumentos y aspectos principales a lo largo de los últimos cincuenta años en las políticas públicas para el desarrollo en las zonas rurales (Cuadro 1).

Los primeros enfoques modernizadores en los años cincuenta sirvieron de preludio a la incidencia directa en la transformación de las explotaciones agrarias. Ésta tuvo como expresión más relevante la 'revolución verde' durante la década de

\footnotetext{
${ }^{3}$ Las propuestas ruralistas y los nuevos argumentos de intervención expuestos podemos calificarlos de 'latinoamericanos', pues su construcción se nutre de la experiencia acumulada y de las reflexiones provistas por actores de un amplio número de países en este subcontinente. Las valoraciones y reflexiones de los dos últimos apartados sí están más sesgadas por la realidad rural centroamericana, y en especial la nicaragüense, fruto de la experiencia profesional y de investigación durante los últimos diez años del autor.
} 


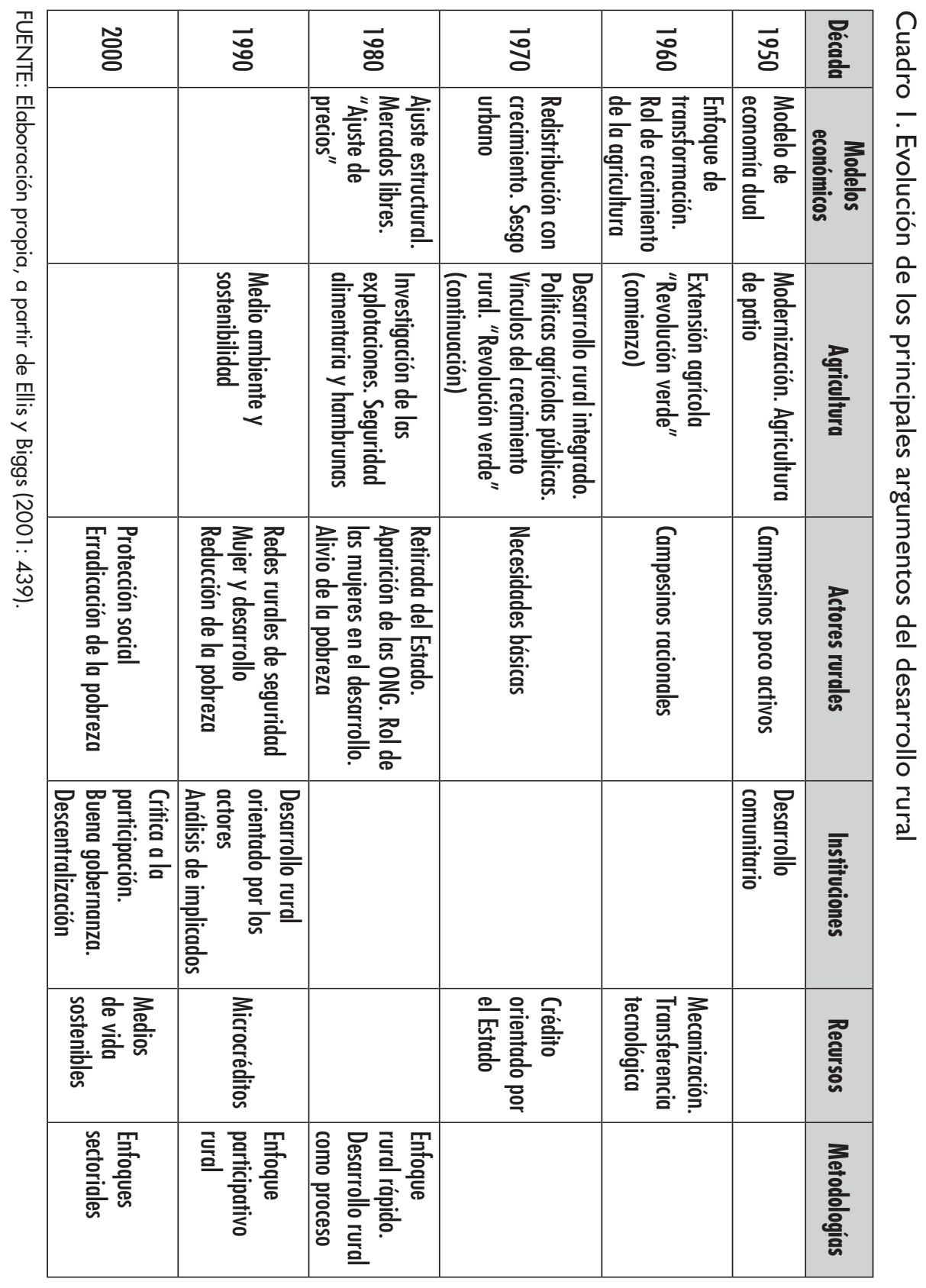


los sesenta. Las zonas rurales estuvieron asociadas unívocamente a la actividad agraria $y$, en consecuencia, la mejora de los niveles de vida debía lograrse con la canalización masiva de insumos de producción y conocimientos a los agricultores y campesinos. En la década de los setenta se incorporan otros factores en las acciones de intervención, como la incidencia en las necesidades básicas de la población de estas zonas y la canalización de recursos financieros, todo ello con una fuerte presencia e intervención del Estado.

La siguiente década supuso un contundente cambio de orientación en la acción estatal. Las políticas de ajuste estructural y liberalización financiera y comercial conducen a la reducción del aparato público al mínimo, con frecuencia, en países donde la presencia, de por sí, ya era limitada. Comienzan a surgir iniciativas de ONG que tratan de suplir los vacíos dejados por la retirada de la institucionalidad pública, sobre todo en el ámbito local. La cercanía a la problemática y a los actores locales, junto con la aparición de estudios sobre la multidimensionalidad de la pobreza, sitúa a esta cuestión en el centro de las intervenciones de desarrollo y facilita la aparición de nuevos instrumentos de diagnóstico e identificación de problemas, como el 'enfoque rural rápido' (rapid rural appraisal) y el 'enfoque participativo rural', en coherencia con la relevancia de la participación.

La década de los noventa supone un paso adelante en la identificación de nuevos factores que inciden en la pobreza rural. La canalización de recursos financieros encuentra en las microfinanzas nuevos mecanismos e instrumentos de apoyo, más flexibles y cercanos que los ofrecidos por los sistemas bancarios formales. La idea de 'población rural' deja de circunscribirse a la acción de los agricultores y campesinos, y nuevos colectivos comienzan a ser tenidos en cuenta. La visibilización del rol de la mujer y el análisis de las redes sociales a nivel local confieren un mayor sesgo sociológico y una mayor relevancia a la institucionalidad local en las intervenciones de desarrollo.

En los aportes más recientes, la institucionalidad local adquiere un mayor peso. La gobernabilidad y la gobernanza ${ }^{4}$ en los territorios rurales se sitúan en el cen-

\footnotetext{
${ }^{4}$ Conviene distinguir de manera sucinta ambos términos. La gobernabilidad refleja la capacidad de una sociedad para afrontar y gestionar los procesos de cambio y transición, y enfatiza el rol del Estado en la canalización de las demandas de la sociedad a través de instituciones democráticas. La gobernanza hace hincapié en el proceso y las reglas que delimitan la interacción entre todos los actores sociales (incluidos los actores públicos) y, según Stoker (1998), señala la capacidad de esa sociedad para lograr sus objetivos sin necesidad de apoyarse únicamente en el poder o la autoridad gubernamental.
} 
tro de la intervención. Cada vez se pone más énfasis en las interrelaciones entre actores locales. Con esa meta, multitud de iniciativas de desarrollo han tratado de estimular espacios comunes de planificación, gestión y concertación, así como acciones para la creación de capacidad institucional y de 'empoderamiento' colectivo e individual. Con ellas se aspira a impulsar la proactividad y la iniciativa de los actores locales en la búsqueda y aplicación de formas innovadoras de acción económica, política y social.

En lo económico, la dependencia de la actividad agraria, fuente primordial de ingresos para la subsistencia de una buena parte de la población, ha centrado durante décadas la atención de las iniciativas de desarrollo. El énfasis en estas fuentes agrarias de renta ha desviado la atención de otro tipo de fuentes, invisibilizadas por su marcado carácter de informalidad, pero con un enorme valor como complemento de unas rentas agrarias inciertas y muy inestables.

Esta evolución en los argumentos de intervención también es sintomática de un mejor conocimiento sobre dinámicas territoriales rurales. Las inversiones tangibles y visibles en activos físicos resultaban necesarias pero insuficientes para garantizar la autonomía y sostenibilidad de los cambios. Estas evidencias han generado un nuevo 'estado de opinión' sobre qué intervenciones son más apropiadas para incentivar los procesos de transformación estructural en zonas rurales, dando lugar al 'enfoque territorial del desarrollo rural' o a lo que denominamos 'enfoque renovado para el desarrollo de las zonas rurales'.

\subsection{Elementos de un 'enfoque renovado del desarrollo rural'}

Para distinguir qué procesos de transformación estructural implica el apoyo renovado del desarrollo en las zonas rurales debemos tener presente la naturaleza polisémica ${ }^{5}$ del término 'desarrollo rural'. Dejaremos a un lado la elaboración de un concepto teórico en torno al 'desarrollo rural' y nos enfocaremos en esbozar qué tipo de transformaciones se trata de inducir en estas zonas (qué, para qué) y qué aspectos instrumentales y operativos (cómo) implican este enfoque renovado.

\footnotetext{
${ }^{5}$ Su aplicación para designar un concepto teórico, una política pública y unos procesos de cambio en estas áreas, además de la evolución constante de su enfoque, dificultan la distinción clara entre medios y fines de las intervenciones (DELGADO, 2004).
} 
Distinguimos los procesos relacionados con la transformación estructural que se trata de inducir en las zonas rurales, de los procesos asociados explícitamente con las cuestiones metodológicas 6 .

Las nuevas tendencias de intervención pública en las zonas rurales inciden en dos grupos de procesos de transformación estructural: una transformación institucional y una transformación productiva. La transformación productiva comporta revalorizar los recursos locales y la diversificación de la economía territorial; asumir la demanda exógena como motor de transformación; ahondar los vínculos urbanos-rurales; y promover una gestión sostenible de los recursos naturales. La transformación institucional implica una mayor autonomía territorial y delegación de responsabilidades a los actores locales; una mayor implicación de la población en la toma de decisiones (enfoque ascendente); la formalización de una alianza entre agentes locales (partenariado local); y una mayor coordinación entre agentes dentro del mismo territorio (coordinación horizontal) y con organismos externos (coordinación vertical). Identificamos a su vez tres ejes transversales: el impulso a respuestas locales innovadoras para esas transformaciones, un enfoque integrado y multisectorial, y una revitalización amplia desde una lógica de competitividad territorial.

Los procesos de cambio referidos al instrumento de intervención implican: la definición de territorio, como objeto central de intervención, siguiendo criterios de dimensión óptima, homogeneidad territorial y delimitación ascendente; la creación de un organismo local de desarrollo rural, en forma de partenariado establecido y organizado por los propios agentes locales; el impulso a las redes y a la cooperación entre territorios; y el reconocimiento de la heterogeneidad rural, que permita respuestas diferenciadas por territorios rurales.

\subsection{Un mapa institucional del 'enfoque renovado del desarrollo rural'}

Múltiples son las iniciativas públicas que dan cuerpo a este nuevo enfoque. Dejando a un lado la experiencia europea de LEADER (JOUEN, 1999; ESPON, 2005), en cierta forma catalizadora del nuevo enfoque, y el trabajo de la OCDE cuestionando la emergencia de un 'nuevo paradigma rural' (OCDE, 2002; 2006a; 2006b), esta corriente de 'nuevas políticas rurales' ha permeado también en

\footnotetext{
${ }^{6}$ Esta propuesta se sustenta en los aportes de Schejtman y Berdegué (2003), Sepúlveda et al. (2003), Delgado (2004), Romero y Ferrero (2004) y Phong et al. (2007). Una exposición más detallada puede encontrarse en Ambrosio Albalá (2007).
} 
el ámbito de la cooperación al desarrollo con el objeto de incidir en la lucha contra la pobreza ${ }^{7}$.

Los organismos internacionales han incorporado nuevos enfoques en sus documentos estratégicos y programas de desarrollo. El Banco Mundial trabaja desde mediados de la década de los noventa en el enfoque del 'desarrollo orientado localmente' (Community Driven-Development, CDD), un enfoque muy próximo a la metodología de los 'grupos de acción local' en la UE ${ }^{8}$ (BANCO MUNDIAL, 1997 y 2003). El Banco Interamericano de Desarrollo (BID) está explorando la viabilidad de un enfoque parecido (el Community Driven Rural Development, CDRD), lo que se ha hecho más evidente en la estrategia más reciente, aún en proceso de aprobación (BID, 2005). La propia Unión Europea ha adoptado un enfoque de desarrollo rural como política para sus programas de desarrollo (DGD, 2000; COMISIÓN DE LAS COMUNIDADES EUROPEAS, 2002), tal y como se reconoce en el llamado 'Consenso Europeo para el Desarrollo' asumido por los Estados miembros en 2006 '.

Cabe reseñar también el surgimiento de plataformas y redes de coordinación entre agencias bilaterales y multilaterales en torno al desarrollo rural. A nivel mundial operan la Red de Seguridad Alimentaria y Desarrollo Rural de Naciones Unidas (UN System Network on Rural Development and Food Security), constituida en 1997 y en la que participan las diferentes agencias del sistema de las Naciones Unidas, y la Plataforma Global de Donantes para el Desarrollo Rural (Global Donor Platform for Rural Development) constituida en 2003 con el objeto de mejorar la efectividad de la ayuda internacional en reducir la pobreza rural en los países en desarrollo y apoyar el logro de las Metas del Milenio. Para el ámbito latinoamericano, el BID auspició en marzo de 2000 la constitución del Grupo Interagencial de Desarrollo Rural, con el fin de complementar la acción de las agencias internacionales en desarrollo rural. Las estrategias actuales y futuras de las mayores agencias do-

\footnotetext{
${ }^{7}$ Así lo evidencia el número especial dedicado por la revista Development Policy Review en 2001 (volumen 19, número 4), amén de otras publicaciones (FerRANTI et al., 2005; EcheVERRI y MosCARDI, 2005).

${ }^{8}$ El término 'community' debe entenderse referido a un grupo de personas con intereses diversos pero implicadas en un mismo proyecto y que llevan a cabo las mismas actividades o similares. La heterogeneidad de intereses alrededor del mismo proyecto puede provocar que los grupos compitan entre sí y sea frecuente la necesidad de dirimir conflictos para la acción conjunta (DAHL-OSTERGAARD et al., 2003).
}

9 Publicado en el Diario Oficial de la Unión Europea, 24 de febrero de 2006 (DOUE 2006/C 46/01). 
nantes en Latinoamérica prevén mantener el apoyo en este campo, aunque existen algunas diferencias significativas. ${ }^{10}$

En Latinoamérica esta nueva corriente sobre el desarrollo rural ha tenido un impacto considerable. En múltiples publicaciones se ha explorado la validez de la experiencia europea para las zonas rurales latinoamericanas (RODRíGUEZ, 2000; GIARRACCA, 2001 ; Pérez Correa y Sumpsi, 2002; Pérez y Caballero, 2003; Bandeira et al, 2004; KaY, 2005; SChmitt y BenASAYAG, 2006). Más relevante ha sido el surgimiento de corrientes de pensamiento latinoamericanas que han desarrollado propuestas de interpretación e intervención propias, y que en gran medida comparten algunos de los principios y objetivos sustanciales del enfoque europeo. En estas corrientes se habla de 'nueva ruralidad' (IICA, 2000; PÉrez Correa y FARAH, 2004; ECHEVERRI y RiBERO, 2002), 'desarrollo rural territorial' (SCHEJTMAN y BERDEGUÉ, 2003) o de 'enfoque territorial del desarrollo rural' (SEPúlvedA et al., 2003; JANVRY y SADOULET, 2004). Entre los principales centros de investigación y redes de trabajo que han dado lugar a estas corrientes, y con el riesgo de excluir otros organismos relevantes, mencionaremos sólo al Instituto Interamericano de Cooperación Agrícola (IICA), el Instituto de Estudios Rurales (IER) de la Universidad Javeriana en Colombia y el Centro Latinoamericano para el Desarrollo Rural (RIMISP) en Chile.

Así mismo, las organizaciones no gubernamentales de mayor entidad en Latinoamérica también han priorizado en sus intervenciones cuestiones estrechamente relacionadas con una visión renovada del desarrollo rural. Durante la última década, las líneas de trabajo priorizadas han incidido en el apoyo a la participación ciuda-

\footnotetext{
10 En un análisis comparado de las estrategias de desarrollo rural de las principales agencias internacionales (Banco Mundial, FIDA, BID, FAO, IICA, CIDA, USAID y Unión Europea) elaborado por el BID (2003) se indica que todas ellas coinciden en vincular sus estrategias con el logro de una reducción significativa de la pobreza y en reconocer la importancia para el desarrollo de las zonas rurales de un entorno macroeconómico estable, de las estrategias de vida de los hogares rurales, de gobiernos locales y regionales con suficientes capacidades institucionales y del papel de la agricultura y de la creciente importancia de otras actividades rurales no agrícolas. Las divergencias están referidas a los siguientes aspectos: (i) coherencia del enfoque territorial con las líneas estratégicas priorizadas: BID, Banco Mundial, IICA y UE son más ruralistas, mientras que CIDA, FAO y USAID, a pesar de la denominación 'rural' mantienen estrategias agrarias; (ii) importancia del desarrollo institucional, asociado al perfeccionamiento de mercados rurales, establecimiento de encadenamientos y de relaciones intersectoriales, plataformas de concertación público-privados y construcción de espacios de ciudadanía, participación y democracia local: Banco Mundial, BID, FIDA e IICA constituyen un núcleo duro institucional, y CIDA y USAID enfocan la mejora institucional referida al perfeccionamiento de los mercados (costes de transacción); y (iii) rechazo a visiones unidimensionales de las relaciones Mercado-Sociedad civil-Estado e impulso a instituciones de arbitraje: USAID y CIDA enfatizan el papel del mercado; el Banco Mundial, el BID y la UE, el rol de la sociedad civil y/o del Estado, caso de IICA y de FAO (BID, 2003).
} 
dana y la gobernabilidad local (89 por ciento de las organizaciones); la agricultura sostenible, el manejo sostenible de recursos naturales y la seguridad alimentaria (67 por ciento); y el desarrollo institucional de las contrapartes, en términos de liderazgo, cabildeo y desarrollo de redes (50 por ciento) (BIEKART, 2005).

Creemos que el panorama institucional expuesto sugiere un renovado interés sobre la problemática rural. Avanzaremos en la delimitación de este renovado enfoque en el caso latinoamericano.

\section{Nuevos argumentos y políticas para la intervención pública en las zonas rurales latinoamericanas}

Hemos insistido en el cambio de percepciones en torno a las dinámicas territoriales rurales de forma genérica. Haremos una revisión a las tendencias observadas en América Latina. A la luz de la experiencia europea, dos aspectos nos parecen relevantes: la visibilización de los desequilibrios entre zonas rurales y la emergencia de propuestas ruralistas autóctonas.

\section{I. Hacia la construcción de una perspectiva latinoamericana del principio de cohesión social}

Si hubiese que identificar un punto de inflexión clave en la política para el medio rural en la Unión Europea, habría que situarlo en la inclusión del principio de cohesión social y económica en el Acta Única Europea en 1986. Con ello se justificó la necesidad de construir una política regional que redujera las diferencias entre los niveles de desarrollo de las diversas regiones y el retraso de las regiones menos favorecidas, incluidas las zonas rurales. De ahí se consideró a las zonas rurales como 'áreas desfavorecidas' y se las benefició con un volumen importante de fondos comunitarios para reducir sus carencias en infraestructuras.

Las 'asimetrías regionales', 'estructurales' o de desarrollo, forma habitual de referirse a los desequilibrios territoriales en Latinoamérica (GIORDANO et al., 2004; ALADI etc., 2005; FILPPO, 2006), no han sido argumentos habituales para justificar la intervención pública en sus zonas rurales. A pesar de ello, cada vez más se asume el alcance real de estos desequilibrios como obstáculos al desarrollo y progresivamente aparecen referencias, aproximaciones a la corrección de desequilibrios y promoción de la cohesión social e instrumentos comunes al enfoque de 
política regional comunitaria en ciertos esquemas latinoamericanos de integración supranacional ${ }^{1 !}$.

En años recientes la 'cohesión social' comienza a ser considerada entre las aspiraciones manifiestas en las declaraciones de cumbres presidenciales y se están dando los primeros pasos para crear fondos específicos que incidan en la corrección de los desequilibrios. Se trata de uno de los aspectos estratégicos priorizados por la Unión Europea en sus relaciones con el subcontinente latinoamericano y en ello se puso especial énfasis durante las dos últimas Cumbres de Jefes de Estado de la UE y Latinoamérica ${ }^{12}$ (COMISIÓN EUROPEA, 2005). Las resultantes Declaraciones de Guadalajara (2004) y de Viena (2006) animaron a introducir en la agenda política la meta de la cohesión social a través del fomento de la inversión social y de un nivel adecuado de gasto público para los sectores sociales (en términos de infraestructura básica y acceso a los servicios sociales), tratando de evitar una dependencia excesiva del financiamiento externo y asumiendo la necesidad de políticas fiscales que permitieran una mejor distribución de la riqueza y garantizaran niveles adecuados de gasto social.

En el terreno político latinoamericano se comienza a asumir esta 'cohesión social' como meta deseable entre los responsables políticos de carteras ministeriales del ámbito social ${ }^{13}$, en declaraciones presidenciales ${ }^{14} y$ en órganos consultivos de

11 En Latinoamérica los esquemas institucionales de integración entre estados, al estilo de la Unión Europea, son calificados de 'integración regional'. Para mantener un criterio uniforme, a lo largo de este apartado evitaremos usar el término 'regional'.

${ }^{12}$ Como resultado de la Tercera Cumbre se inició el Programa Regional para la Cohesión Social en América Latina (EUROSOCIAL), iniciativa de cooperación técnica de la Comisión Europea para promover la cohesión social en América Latina a través del intercambio de experiencias entre administraciones públicas responsables de la administración de la Justicia, la Educación, el Empleo, la Fiscalidad y la Salud. Este programa culminará en 2009 y está dotado con más de 36 millones de euros. [Web en línea] <www.programaeurosocial.eu> [Consulta: 15-11-2006]. Con el apoyo de este programa, la CEPAL ha publicado una de las primeras reflexiones sobre el interés y potencial de la cohesión social como principio de políticas publicas en el subcontinente latinoamericano (OTTONE, 2007).

${ }^{13}$ En términos similares a la Declaración de Guadalajara, los ministros latinoamericanos responsables de políticas sociales acordaron la Declaración de Santa Clara (2004) en el V Foro de Consulta de Ministros de Desarrollo Social de América Latina y El Caribe, celebrado en Santa Clara, Lima-Perú, el 1 y 2 de mayo de 2004.

${ }^{14}$ Véanse los compromisos alcanzados en la Primera Cumbre de la Comunidad Sudamericana de Naciones, celebrada en Brasilia el 30 de septiembre de 2005 (CSN, 2005); en la Cumbre de la Comunidad Andina de Naciones celebrada en 2004 (CAN, 2004); y en la XXVIII Reunión Ordinaria 
los esquemas de integración ${ }^{15}$. También se están celebrando foros de discusión y encuentros de alto nivel ${ }^{16}$ para analizar la manera de abordar la corrección de las desigualdades y la necesidad de elaborar políticas específicas que incidan en la cohesión social. En distinto grado, puede tratarse de una declaración de intenciones o de un principio de acción. Pero a pesar de no encontrar una referencia explícita continuada en las declaraciones oficiales ${ }^{17}$, se ha logrado mantener una aproximación relativamente innovadora en la corrección de las asimetrías nacionales y regionales (CAN, 2006).

Precisamente en el marco de los acuerdos de integración se percibe una mayor receptividad a la corrección de estas asimetrías, en especial, entre los países sudamericanos (ALADI, 2005; ALADI et al., 2005). En el marco de la Comunidad Sudamericana de Naciones, se reconoce que la reducción de las asimetrías entre países se ha convertido en una "condición necesaria para la sostenibilidad y legitimidad de los procesos de integración" (ALADI et al., 2005). Se asume que los tratamientos diferenciados en los intercambios comerciales han resultado insuficientes, pues el aumento en el comercio intraregional no ha logrado reducir las asimetrías estructurales. Para ello se hace necesario nivelar las condiciones en las que compiten los países para que puedan beneficiarse del proceso de integración,

de Jefes de Estado y Presidentes del Sistema de la Integración Centroamericana (SICA) celebrada en Panamá en julio de 2006 (SICA, 2006a).

${ }^{15}$ En la Comunidad Andina de Naciones (CAN), el Consejo Consultivo Andino de Autoridades Municipales (CCAAM) asumió como principios centrales de su agenda de cooperación, entre otros, "la participación en la construcción de una visión andina en torno al desarrollo regional y la competitividad territorial, como sustento de la cohesión social y la gobernabilidad democrática (...) y la evaluación de mecanismos financieros orientados a la promoción del desarrollo local y la cohesión social" (CCAAM, 2005).

16 Entre las acciones más recientes, destacamos los seminarios y conferencias organizados por la Unión Europea con organismos multilaterales de ámbito latinoamericano (UE-BID, 2003; CEPAL-UE, 2004); como trabajo preparatorio de la Cuarta Cumbre UE-Latinoamérica en Viena, la Conferencia de Alto Nivel "Promover la cohesión social: las experiencias de la Unión Europea y de América Latina y el Caribe" celebrada en Viena en 2006 (DGRE, 2006); y el Seminario Cohesión Social en Iberoamérica celebrado en Madrid el 19 y 20 de junio de 2007 y organizado por la Secretaría General Iberoamericana, como encuentro preparatorio para la XVII Cumbre Iberoamericana a celebrar en Chile en octubre de 2007.

${ }^{17}$ Véase la Declaración de Cochabamba de la Segunda Cumbre de la Comunidad Sudamericana de Naciones, celebrada en diciembre de 2006 (CSN, 2006) y la Declaración Final de la XXIX Reunión Ordinaria de Jefes de Estado y Presidentes del Sistema de la Integración Centroamericana (SICA) celebrada en San José de Costa Rica en diciembre de 2006 (SICA, 2006b). 
conjugando políticas de acceso a mercados, políticas de tratamiento de asimetrías estructurales, y políticas de tratamiento de asimetrías derivadas de políticas públicas. Entre los instrumentos considerados para implementarlas ${ }^{18}$, se prevé la necesidad de dotar fondos de financiación compensatoria y un fondo solidario para incidir en una política común de convergencia estructural (ALADI et al., 2005).

En este aspecto ya ha habido algunos pasos prometedores. La experiencia más avanzada se ha producido en el MERCOSUR, mediante la creación de un Fondo para la Convergencia Estructural ${ }^{19}$ (FOCEM) con el objetivo de "promover la convergencia estructural; desarrollar la competitividad; promover la cohesión social, en particular de las economías menores y regiones menos desarrolladas, y apoyar el funcionamiento de la estructura institucional y el fortalecimiento del proceso de integración" (CONSEjO del MeRCADO COMÚN, 2005a). A pesar del sustancial avance que representa la dotación de un fondo específico, las carencias de condiciones institucionales y presupuestarias adecuadas socavan la efectividad y viabilidad de la iniciativa (FILIPPO, 2006).

Ahí radica posiblemente una de las dificultades mayores para que un enfoque de política regional pueda establecerse en las iniciativas de integración latinoamericana. Sobre ellas volveremos más adelante.

\subsection{Las nuevas propuestas latinoamericanas sobre las zonas rurales}

Las propuestas para revitalizar las zonas rurales latinoamericanas comienzan a transcender los límites de la actividad agraria. A este respecto, tres referentes son

\footnotetext{
${ }^{18}$ La propuesta de instrumentos contemplan tres tipos: instrumentos financieros, en la línea conocida de los fondos estructurales y de cohesión de la Unión Europea; cooperación horizontal para la generación de 'bienes públicos regionales' (coordinación macroeconómica, armonización de normativa fitosanitaria, establecimiento de redes aeroportuarias, infraestructura regional para el transporte, investigación agrícola, entre otros); y cooperación técnica internacional no reembolsable (ALADI et al., 2005).

19 En 2003 el Consejo del Mercado Común del MERCOSUR se propuso estudiar el establecimiento de "Fondos Estructurales destinados a elevar la competitividad de los socios menores y de aquellas regiones menos desarrolladas" (CONSEJO DEL MERCADO COMÚN, 2003). De ahí surgió la creación de un Fondo de Convergencia Estructural (FOCEM) (CONSEjO del MERCADO COMÚN, 2004), dotado con 100 millones de dólares y con una duración prevista de 10 años (CONSEJO DEL MERCADO COMÚN, 2005a). El FOCEM podrá financiar proyectos presentados por los Estados miembros en cualquiera de los cuatro programas contemplados: Convergencia Estructural, Desarrollo de la Competitividad, Cohesión Social y Fortalecimiento de la Estructura Institucional y del Proceso de Integración (CONSEJO DEL MERCADO COMún, 2005a y 2005b).
} 
fundamentales: las corrientes de la 'nueva ruralidad', 'desarrollo rural territorial' y el 'enfoque territorial del desarrollo rural'.

\section{a. La perspectiva de la 'nueva ruralidad'}

Esta corriente se nutre, sobre todo, de los aportes elaborados desde el Instituto de Estudios Rurales (IER) de la Pontificia Universidad Javeriana de Colombia, su figura más reconocida es la Prof. Edelmira Pérez Correa (Pérez Correa, 2001, 2002; Pérez Correa y Farah, 2004) y el principal medio de comunicación científica es Cuadernos de Desarrollo Rural. Representa un primer intento de conceptualizar una nueva 'ruralidad latinoamericana' con aportes autóctonos y su aparición es casi contemporánea del enfoque europeo (RAMOS y DelGADO, 2005).

La aproximación desde el IER enfatiza los aspectos sociológicos y colectivos en los procesos de transformación rural. Las líneas fundamentales de investigación se centran en las relaciones y estructuras de poder en el medio rural y el comportamiento de los actores sociales, los sistemas agroalimentarios locales y las dinámicas empresariales (tecnología, comercialización) de las unidades de producción campesina, las cooperativas y los agentes económicos del sector solidario, la planificación y programación participativa de intervenciones en las áreas rurales y el estudio de la participación comunitaria en los procesos de cambio rural y en la producción del conocimiento local.

Pérez Correa (2001 y 2002) construye la 'nueva ruralidad' desde una visión 'meta' de las tendencias y cambios rurales. Esta autora contempla el desarrollo de las zonas rurales fundamentalmente como un proceso de transformación en el que, para comprender las dinámicas de cambio presentes y futuras, es imprescindible mantener una perspectiva histórica, holística y sistémica de la realidad rural. Impulsar ese proceso de transformación demanda reconocer la heterogeneidad de las zonas rurales (entre sí y dentro de ellas), requiriendo políticas diferenciadas que reconozcan y aprovechen esa diversidad. Dentro de esa heterogeneidad, también se reconoce la pluralidad de actores, entre quienes los actores locales deben asumir una mayor responsabilidad, y de representaciones colectivas sobre una misma realidad, incorporando la existencia de interpretaciones conflictivas y la mayor responsabilidad que, en especial, deben asumir los actores locales (PÉrEZ CORREA, 2002: 22). 


\section{b. La perspectiva del 'desarrollo rural territorial'}

El aporte fundamental es de Schejtman y Berdegué (2003) y la institución referente es el Centro Latinoamericano para el Desarrollo Rural (RIMISP), organismo clave en el impulso a la nueva visión de la ruralidad latinoamericana. Su principal vehículo de difusión sobre los procesos de transformación rural latinoamericanos es el Boletín Intercambios. La perspectiva es considerada un intento de síntesis de los aportes de la 'nueva ruralidad' y del enfoque europeo del desarrollo rural ascendente (RAMOS y DelGADO, 2005).

Este enfoque se nutre de aportes teóricos que estudian los vínculos entre la actividad económica y la localización espacial. En especial, son de interés las contribuciones sobre el desarrollo económico local inspiradas en el estudio de las externalidades que generan economías de escala externas a la empresa pero internas al territorio, de los entornos o regiones de aprendizaje y la influencia del aprendizaje colectivo en la generación de innovación como fuente de competitividad, y de las consideraciones sobre la gobernanza englobadas en los activos institucionales de un territorio ${ }^{20}$.

De aquí elaboran una definición del desarrollo territorial rural, como "proceso de transformación productiva e institucional de un espacio rural determinado, cuyo fin es reducir la pobreza rural" (p.21), estableciendo dos pilares fundamentales: la transformación productiva, con el objeto de "articular competitiva y sustentablemente la economía del territorio con mercados dinámicos", y el desarrollo institucional, cuyo propósito es "estimular la concertación de los actores locales entre sí y entre ellos y los agentes externos y modificar las reglas formales e informales que reproducen la exclusión de los pobres en los procesos y en los beneficios de la transformación productiva" (SCHEJTMAN y BERDEGUÉ, 2003: 21).

Aun manteniendo una aproximación amplia, desde RIMISP se enfatizan los aspectos económicos e institucionales de la transformación rural: el acceso de pequeños productores y empresarios rurales a mercados dinámicos; el impacto de los cambios estructurales y condiciones fundamentales para facilitar la cooperación local; las relaciones entre los nuevos movimientos sociales y las organizaciones e instituciones en el marco de la gobernanza local; el empleo y el ingreso rurales no agrícolas a

\footnotetext{
${ }^{20}$ Las referencias fundamentales citadas por Schejtman y Berdegué (2003) son los trabajos sobre aglomeración industrial (KRUGMAN, 1995), los clusters o distritos industriales (PORTER, 1998), los nuevos distritos industriales (BECATTINI y RULLANI, 1993), los milieu o regiones de aprendizaje (MAILAT, 1995) y las instituciones (NORTH, 1993).
} 
partir de los cambios en las demandas, en especial, de los consumidores urbanos; $y$ las redes y procesos colectivos de reflexión y deliberación crítica como instrumentos del aprendizaje social para el cambio rural.

\section{c. La perspectiva del 'enfoque territorial del desarrollo rural'}

Esta última perspectiva se apoya en los trabajos elaborados en el Instituto Interamericano de Cooperación para la Agricultura ${ }^{21}$ (IICA). Su principal publicación periódica es ComunllCAy dispone de un área Desarrollo Rural Sostenible, entre cuyos objetivos asume la reducción de la pobreza rural, el aumento de la prosperidad rural y la mejora de las capacidades de los habitantes rurales, con la finalidad de acelerar su propio desarrollo por medio del uso sustentable de los recursos naturales.

En coherencia con la misión institucional, esta propuesta responde a tres elementos básicos del mandato del IICA; específicamente: promover el desarrollo sostenible de la agricultura; promover la seguridad alimentaria; y promover la prosperidad rural (SEPÚLVEDA et al., 2003: 70-75). Esta subordinación al mandato institucional ya sugiere un sesgo agrario más explícito que en las perspectivas anteriores, y que es evidenciado a lo largo de la propuesta ${ }^{22}$.

Emana como evolución lógica de los enfoques asumidos por el IICA en las últimas décadas, en especial, de los aportes sobre microplanificación regional y sobre 'nueva ruralidad', en el marco del cual el instituto elaboró una de las primeras propuestas ampliamente reconocidas en la materia (IICA, 2000). Frente a esa propuesta inicial, en los aportes más recientes (ECHEVERRI y RIBERO, 2002; MIRANDA, 2003; SEPúlVEDA et al., 2003) se corrige considerablemente el sesgo hacia la diagnosis de las zonas rurales presente en ese primer aporte ${ }^{23}$. Además, se incorpora el argumento de los desequilibrios estructurales como obstáculos al desarrollo y la

\footnotetext{
${ }^{21}$ El IICA es un organismo especializado del Sistema Interamericano, cuyos fines son estimular, promover y apoyar los esfuerzos de sus Estados Miembros para lograr el desarrollo agrícola y el bienestar rural. Concentra su actividad en seis áreas estratégicas: Desarrollo de los Agronegocios, Políticas y Comercio, Tecnología e Innovación, Sanidad Agropecuaria e Inocuidad de los Alimentos, Desarrollo Rural Sostenible, Información y Comunicación, Educación y Capacitación.
}

${ }^{22}$ A modo indicativo, véase en Sepúlveda et al. (2003) la interpretación del concepto de la 'competitividad territorial' (p.81-85) y de la 'economía del territorio' (p.90).

${ }^{23}$ Sesgo reconocido desde el mismo instituto (SEPúlvEDA et al., 2003) y puesto en evidencia por otros autores (RAmOS y DelGADO, 2005; KAY, 2005). 
perspectiva de la cohesión social y la cohesión territorial (SEPÚlvEDA et al., 2003: 94-95), elementos ausentes en las perspectivas previas. En sus antecedentes se evidencia también una notable influencia de la interpretación y el pensamiento europeos sobre política rural (Saraceno, 2003; Ramos y Delgado, 2005).

De forma esquemática, en el Cuadro 2 recogemos los elementos fundamentales y operativos de las dos últimas aproximaciones. En éstas dos, a diferencia de la primera perspectiva, se explicitan las implicaciones estratégicas y operativas de sus propuestas para la elaboración de políticas públicas.

Cuadro 2: Elementos fundamentales y operativos de dos aproximaciones ruralistas latinoamericanas

\begin{tabular}{|c|c|c|}
\hline & $\begin{array}{l}\text { 'Desarrollo territorial rural' del } \\
\text { RIMISP (SCHEJTMAN y BERDEGUÉ, 2003) }\end{array}$ & $\begin{array}{l}\text { 'Enfoque territorial del desarrollo } \\
\text { rural' del IICA (SEPúlvEDA et al., 2003) }\end{array}$ \\
\hline $\begin{array}{l}\text { Elementos } \\
\text { funda- } \\
\text { mentales }\end{array}$ & $\begin{array}{l}\text {-Competitividad por difusión del progre- } \\
\text { so técnico y del conocimiento } \\
\text { - Innovación tecnológica clave para } \\
\text { elevar productividad } \\
\text {-Carácter sistémico de la innovación } \\
\text {-Demanda externa al territorio } \\
\text {-Vínculos urbanos-rurales } \\
\text {-Desarrollo institucional } \\
\text { - Territorio como construcción social y } \\
\text { expresión de identidad }\end{array}$ & $\begin{array}{l}\text {-Reconstrucción del concepto de lo rural } \\
\text {-De la economía agrícola a la territorial } \\
\text {-Economía territorial y local-rural en las } \\
\text { estrategias de crecimiento nacionales } \\
\text { - Gestión ambiental y servicios ambientales } \\
\text {-De la competitividad privada a la territorial } \\
\text {-Ordenamiento territorial desde la } \\
\text { descentralización } \\
\text {-Cooperación y responsabilidad compartida } \\
\text {-Coherencia entre políticas públicas } \\
\text {-Gestión del conocimiento }\end{array}$ \\
\hline $\begin{array}{l}\text { Criterios } \\
\text { operativos }\end{array}$ & $\begin{array}{l}\text {-Simultaneidad de transformación pro- } \\
\text { ductiva e institucional } \\
\text {-Concepto ampliado de lo rural } \\
\text { - Territorio como espacio con identidad y } \\
\text { proyecto concertado } \\
\text { - Heterogeneidad entre territorios } \\
\text { - Integración de diversidad de agentes } \\
\text { territoriales } \\
\text {-Distintas rutas de salida de la pobreza } \\
\text {-Compleja arquitectura institucional } \\
\text { - Horizonte temporal a medio-largo plazo }\end{array}$ & $\begin{array}{l}\text {-Enfoque territorial holístico (multisecto- } \\
\text { rialidad, intergeneracionalidad, economía } \\
\text { territorial, cohesión territorial y social) } \\
\text {-Enfoque territorial para la gestión conjunta } \\
\text { entre actores (diversidad territorial, actores } \\
\text { locales, capital social, capacidades y capital } \\
\text { humano, nuevos contratos sociales) } \\
\text {-Enfoque territorial para la gestión soste- } \\
\text { nible de recursos naturales (base de la } \\
\text { cohesión territorial, elemento de reducción } \\
\text { de pobreza, heterogeneidad ambiental) }\end{array}$ \\
\hline
\end{tabular}

FUENTE: Adaptación de Schejtman y Berdegué (2003) y Sepúlveda et al. (2003). 


\section{I. Experiencias de políticas y programas públicos para las zonas rurales}

Durante la última década los programas gubernamentales nacionales y las intervenciones de las organizaciones y agencias internacionales de cooperación han desarrollado programas para las zonas rurales latinoamericanas que incorporan algunos de los elementos y estrategias de estas nuevas aproximaciones. Dejando a un lado intervenciones específicas de seguridad alimentaria ${ }^{24}$, entre los programas y procesos desarrollados en los últimos cinco años señalaríamos, a modo indicativo ${ }^{25}$, las siguientes experiencias:

- Por un lado, procesos estratégicos para la implementación de una visión territorial en la definición y coordinación de políticas con incidencia en las zonas rurales; es el caso de Nicaragua, con las Bases para el Desarrollo Rural ${ }^{26}$ (ROMERO y FERRERO, 2004) y el Plan Nacional de Desarrollo Rural Sustentable en Brasil resultado del trabajo impulsado por el Consejo Nacional de Desarrollo Rural Sustentable ${ }^{27}$ (VEIGA, 2001).

- En el ámbito subnacional, experiencias como la Ley de Descentralización y la Ley de Participación Popular en Bolivia impulsaron un proceso de planificación estratégica municipal en todo el país (URIOSTE y BALDOMAR, 1999). Más sesgados hacia el desarrollo económico local cuentan las experiencias del Proyecto de Reducción de la Pobreza y Desarrollo Rural Local (PROLOCAL) en Ecuador; el Programa Red Nacional de Superación de la Pobreza en Municipios Rurales (PRORURAL) en Chile; y en México el Programa de Zonas Marginadas (PÉrez HARO, 2003) y la Ley de Desarrollo Rural Sustentable en 2001 que apoyó la formulación de programas municipales y regionales con el impulso de los

${ }^{24}$ Entre las cuales podemos destacar el Programa Especial de Seguridad Alimentaria (PESA) de la FAO-AECI para los países centroamericanos, el Programa de Seguridad Alimentaria (PSA) en Argentina, los programas Hambre Cero (Fome Zero) y Bolsa Familia en Brasil y el programa Hambre Cero en Nicaragua.

${ }^{25}$ Esta relación de programas se ha beneficiado de la disponibilidad de esta información en los sitios web de los ministerios correspondientes. Es obvio que no es una relación exhaustiva y que nos hemos limitado a programas sobre los cuales hay información accesible.

${ }^{26}$ El equipo técnico español vinculado a INSA-ETEA (Universidad de Córdoba) ha realizado un trabajo similar con el Ministerio de Agricultura y universidades vietnamitas, fruto del cual se han generado unas Bases para el Desarrollo Rural Territorial en Vietnam (PHONG et al., 2007).

${ }^{27}$ Plano Nacional do Desenvolvimento Rural Sustentável y Conselho Nacional de Desenvolvimento Rural Sustentável (CONDRAF) <www.condraf.org.br>. 
Consejos de Desarrollo Rural Sustentable (RUIz, 2002; ECHEVERRI y MOSCARDI, 2005).

- Algunas experiencias han promovido la articulación entre sector privadoy sector público locales. Este fue el caso de las Alianzas Productivas para la Paz (RoJAS RuedA, 2002) en Colombia, retomadas en las iniciativas de Apoyo a Alianzas Productivas y Cadenas Productivas (Agrocadenas), parte de los 'Programas Bandera' del actual Ministerio de Agricultura y Desarrollo Rural colombiano.

- Gran número de los programas latinoamericanos tratan de mejorar la inserción en el mercado y de incentivar la diversificación en las actividades económicas de los campesinos productores y de las unidades de agricultura familiar. Es el caso del Programa de Alivio a la Pobreza e Iniciativas Rurales (PROINDER) en Argentina, el Programa Nacional de Fortalecimiento da Agricultura Familiar (PRONAF) en Brasil (Schmit y BenASAYAG, 2006) y en Chile, los programas de Apoyo a la Inserción Agrícola Familiar al Desarrollo Económico Nacional, el Programa de Desarrollo Campesino (PRODECAM) y el PRODECOP-Secano. En el caso de Colombia, el Programa de Desarrollo Integral Campesino (PDIC) enfatizó la transferencia de competencias y responsabilidades a los gobiernos locales en la gestión de estos programas (VARGAS, 1999).

- El apoyo a la creación de microempresas rurales y a las inversiones necesarias para la actividad empresarial rural también cuenta entre los ejes más apoyados, como sucede en el Proyecto de Apoyo al Desarrollo de la Microempresa Rural (PADEMER) en Colombia y el Programa de Apoyo a los proyectos de Inversión Rural (PAPIR) en México. Probablemente la experiencia más próxima a la iniciativa LEADER sea la desarrollada mediante el programa Uruguay Rural, dirigido a la 'población de escasos recursos' habitante de las zonas rurales y gestionada mediante las llamadas Mesas de Desarrollo Rural28.

- En la línea de generación de capacidades técnicas y de gestión y en la promoción de la articulación de organizaciones locales actúan el Programa de Desarrollo Local (PRODESAL) en Chile; en México se desarrolla desde 2002 el Programa de Fortalecimiento de Empresas y Organización Rural (PROFEMOR) y el Programa de Desarrollo de Capacidades en el Medio Rural (PRODESCA) ${ }^{29}$;

${ }^{28}$ Véase la web del programa 'Uruguay Rural' <www.uruguayrural.gub.uy>.

${ }^{29}$ Estos dos programas PROFEMOR y PRODESCA, junto al PAPIR, integran las intervenciones base del Programa de Desarrollo Rural de la Alianza para el Campo constituida en 2002 por la Subsecretaría 
y con apoyo del BID, el Programa Experiencias Piloto de Desarrollo Rural Local ${ }^{30}$ (EXPIDER), con un mayor énfasis en la creación de organizaciones locales que impulsen la planificación territorial y gestionen su implementación (AMADOR HIDALGO et al., 2003; SUMPSI, 2006b).

En un análisis comparado de programas nacionales con incidencia en la lucha contra la pobreza, Berdegué et al. (2003) identifican elementos comunes que sugieren un cambio de enfoque teórico. En los programas analizados ${ }^{31}$ se observa la incorporación de una visión amplia de la economía rural, el fomento de las distintas estrategias de pluriactividad y de generación de ingresos en los hogares rurales, una mayor sensibilidad a la demanda de los mercados y un menor grado de estatalismo, reconociendo más importancia a la iniciativa empresarial privada.

También los organismos y agencias internacionales han incorporado esta aproximación en los programas financiados. Para los países centroamericanos, Richards (2004) identifica líneas de acción coincidentes en la intervención de estas agencias y distingue entre rutas primarias de salida de la pobreza y estrategias de desarrollo rural secundarias (Cuadro 3).

de Desarrollo Rural de la Secretaría de Agricultura, Ganadería, Desarrollo Rural, Pesca y Alimentación (SAGARPA) del gobierno mejicano.

${ }^{30}$ La primera fase de EXPIDER (2003-2005) se ejecutó en zonas rurales de Bolivia, Ecuador y Honduras. La segunda fase (2006-2008) se ejecuta actualmente en territorios de Costa Rica, Venezuelay Chile.

31 La muestra estuvo conformada por programas de fomento productivo, Fondos de Inversión Social, programas de transferencias directas, programas de conservación del medio ambiente y promoción de servicios ambientales y programas de promoción de la participación municipal. Como experiencias en el primer área se estudian las Cajas Rurales de Ahorro y Préstamos, Honduras; Programa de Modernización de los Servicios Agropecuarios (PROMSA), Ecuador; Programa de Desarrollo Integral Campesino (PDIC), Colombia; y Programa de Agricultura Familiar (PRONAF), Brasil. Como fondos de inversión social, la Red de Solidaridad Social, Colombia; Programa Nacional de Solidaridad (PRONASOL), México y el Fondo de Compensación y Desarrollo Social (FONCODES), Perú. Como programas de transferencias directas, el PROGRESA, México y el Seguro Social Rural, Brasil. Como programas ambientales Programa Nacional de Manejo de Cuencas Hidrográficas (PRONAMACHS), Perú y Ecomarkets, Costa Rica. Y en el área de la participación municipal, Consejos del Desarrollo Local (CDL) del PRODECOP-INDAP, Chile y la participación indígena en Cantón Guamote, Ecuador (BERDEGUÉ et al., 2003). 
Cuadro 3: Rutas de salida y estrategias de desarrollo rural en Centroamérica por proponentes principales

\begin{tabular}{|l|l|l|l|}
\hline \multicolumn{2}{|l|}{ Rutas } & Proponentes principales \\
\hline \multirow{4}{*}{ Primarias } & \multicolumn{2}{|l|}{ Agricultura familiar } & IFAD, IFPRI, BM, ONGs \\
\cline { 2 - 4 } & $\begin{array}{l}\text { Dirigido por el crecimiento } \\
\text { (empleo para los no pobres) }\end{array}$ & Agricultura comercial & USAID, BM, DFID, FAO, FIDA \\
\cline { 2 - 4 } & Migración urbana & Diversificación (ERNA) & USAID, BM, DFID, BID \\
\cline { 2 - 4 } & Bienestar (protección social) & BM, USAID \\
\hline \multirow{3}{*}{ Secundarias } & Desarrollo regional & FIDA, BM, BID, sociedad civil \\
\cline { 2 - 4 } & Gobierno y empoderamiento & Janvry y Sadoulet \\
\cline { 2 - 4 } & Coordinación de los donantes & EU, IFAD, DFID \\
\hline
\end{tabular}

LEYENDA: (BID) Banco Interamericano de Desarrollo; (BM) Banco Mundial; (DFID) UK Department for International Development, Departmento para el Desarrollo Internacional del Gobierno del Reino Unido; (ERNA) Empleo Rural no Agrícola; (EU) European Union, Unión Europea; (FAO) Food and Agriculture Organization of the United Nations, Organización de las Naciones Unidas para la Alimentación y la Agricultura; (IFAD) International Fund for Agricultural Development, Fondo Internacional para el Desarrollo Agrícola; (IFPRI) International Food Policy Research Institute; (ONG) Organizaciones No Gubernamentales; (UN) United Nations, Naciones Unidas; (USAID) United States Agency for International Development. FUENTE: Richards (2004).

En las primeras, se incluye el apoyo a las agriculturas campesinas y de pequeña escala, a explotaciones con mayor capacidad para insertarse en el mercado y a la diversificación hacia actividades rurales no agrícolas, a los migrantes rurales hacia las zonas urbanas, y al aumento de la inversión social en áreas con graves carencias. Entre las segundas rutas, se contempla la creación de entornos y contextos con mejores oportunidades de educación, de salud y de inversión; la incidencia en el empoderamiento de la población más pobre para mejorar su capacidad de negociación política y económica; y la mejora de la coordinación entre agencias de desarrollo para corregir las duplicidades e ineficacias en las intervenciones y asegurar la coordinación con las estrategias y políticas nacionales (RICHARDS, 2004). 


\section{Valoración crítica de los nuevos argumentos y propuestas para las zonas rurales latinoamericanas}

No obstante las tendencias de cambio observadas, nos atreveríamos a brindar, desde una perspectiva europea y con nuestro limitado conocimiento de la realidad rural latinoamericana, algunas valoraciones sobre las perspectivas para una implementación efectiva de estas propuestas.

\section{I. Limitantes para una política regional latinoamericana}

En los países latinoamericanos persisten algunas carencias institucionales y rasgos estructurales que dificultan la reducción de los desequilibrios territoriales y que merecen ser destacadas.

\section{a. Limitantes institucionales para una política regional}

En primer lugar hay que contemplar que el avance en la consolidación de las iniciativas de integración condiciona tanto la elaboración de políticas regionales como la efectividad de su impacto ${ }^{32}$.

Los instrumentos de integración existentes en Latinoamérica que aspiran a grados crecientes de unión política (MERCOSUR, CAN, MCCA y CARICOM), pueden caracterizarse actual mente como uniones aduaneras en tránsito hacia modalidades más profundas de integración económica, política y sociocultural. Avanzar hacia un esquema de integración como el europeo, referente inmediato de los esquemas latinoamericanos, implica la aceptación de grados crecientes de asociación política, social y cultural jurídicamente vinculantes, incluyendo la creación de niveles supranacionales donde no se anulen pero sí se compartan las soberanías nacionales. La falta de supranacionalidad de las normas y órganos comunitarios es la carencia fundamental de que adolecen los esquema de integración latinoamericanos (FILIPPO,

\footnotetext{
${ }^{32}$ Ante la escasa consolidación de estos esquemas latinoamericanos de integración, hubiera sido más apropiado abordar este análisis explorando las iniciativas nacionales o las impulsadas desde organismos internacionales. Creemos que la magnitud de las inversiones públicas y el volumen de recursos necesarios para una política regional de gran calado, excede las capacidades de buena parte de los Estados latinoamericanos. Téngase en cuenta que, en la experiencia europea, ha sido gracias a la integración en la UE que los Estados más atrasados han accedido a una ingente cantidad de recursos para acometer las inversiones y reformas estructurales necesarias. De ahí que la aproximación supranacional sea pertinente.
} 
2006). En buena medida, la falta de vinculación de los acuerdos supranacionales deriva de las asimetrías de poder-dependencia ${ }^{33}$ entre los estados miembros. Entre los esquemas latinoamericanos, el caso del MERCOSUR resulta paradigmático ${ }^{34}$ de las carencias en el ámbito de la supranacionalidad.

La preeminencia de los poderes ejecutivos en los modos operativos de los acuerdos intergubernamentales provoca la persistencia de un voluntarismo político que confiere una considerable debilidad institucional a largo plazo a las decisiones fundamentales de los acuerdos ${ }^{35}$. Además, las normas constitucionales vigentes en los Estados miembros no siempre garantizan la vigencia de normas comunitarias de carácter supranacional. Persisten múltiples trabas técnicas y regulatorias que impiden un comercio verdaderamente libre entre sus miembros. La escasa convergencia regulatoria en materia macroeconómica (cambiaria, tributaria, etc.) y la práctica ausencia de coordinación, armonización y unificación de las tecnologías y las reglas que orientan los procesos económicos, aspectos sujetos a las interacciones entre Estados miembros, condicionan de forma decisiva la emergencia de un marco estable para la inversiones y crecimiento económico.

A todo ello hay que añadir la débil autoridad de los órganos comunitarios supranacionales, en gran medida por la escasez en la dotación de una financiación estable, autónoma y suficiente. Si el monto de la financiación es un aspecto económico, la vigencia de una financiación suficiente es una decisión eminentemente política. Estas carencias en la compatibilidad normativa se traduce en la inexistencia o el

33 Para explicar el concepto de 'asimetría de poder-dependencia' nos referimos textualmente a la definición de Filippo (2006: 82): "[Las asimetrías de poder-dependencia] se predican respecto de los Estados Miembros que son titulares de poderes soberanos sobre territorios claramente delimitados. El concepto de poder se define aquí como la capacidad efectiva que tienen los Estados de imponer sus reglas de juego en el seno de las relaciones internacionales con otros Estados, y este poder está directamente relacionado con el grado de dependencia que los otros Estados Miembros experimenten respecto de ellos. El concepto de dependencia se refiere aquí a la intensidad de la necesidad que tiene cada Estado de interactuar con otro u otros para preservar su existencia en las dimensiones principales afectadas por esa interacción y por esa vía de aceptar las reglas de juego establecidas en el ámbito internacional específico que corresponda."

${ }^{34}$ En el caso del CARICOM existe una detallada caracterización y un extenso reconocimiento en los tratados fundamentales, pero con una formulación ambigua y una operativización escasa. En el MCCA, "la frondosa proliferación de normas y organismos del SICA depende en grado decisivo de la provisión de fondos provenientes de la cooperación internacional" (FILPPO, 2006: 92).

${ }^{35}$ Para el caso centroamericano, véase el estudio realizado por Pedro Caldentey del Pozo (2004) en el marco del proyecto de investigación "La integración centroamericana: beneficios y costos" auspiciado por el Sistema de Integración Centroamericana (SICA) y la CEPAL. 
insuficiente avance efectivo en el reconocimiento de legislaciones recíprocas en campos tales como la validez de títulos universitarios, de derechos laborales y de seguridad social, de acceso legal a los servicios de salud, a los tribunales de justicia, aspectos fundamentales para la creación de mercados comunes de trabajo. En síntesis, la certidumbre sobre las condiciones de acceso a los mercados internos, la generación de confianza en unas reglas creíbles y previsibles que favorezcan la realización de inversiones a largo plazo, la transposición de las normas comunes a las legislaciones nacionales y la restricción de las tendencias al unilateralismo se convierten en elementos críticos para la convergencia entre los países (GIORDANO et al., 2004; FILPPO, 2006).

\section{b. Limitantes estructurales para una política regional}

Las asimetrías estructurales tienen algunas características especiales en América Latina. Estos desequilibrios tienen lugar en el seno de un continente caracterizado por ingresos medios y bajos, en el que, en algunos casos, el tamaño de los países (en población y extensión) no está relacionado estrechamente con su nivel de desarrollo, y donde en muchos países existen importantes asimetrías internas en el nivel de desarrollo de las regiones (ALADI et al., 2005).

Con una aproximación más detallada identificamos factores estructurales específicos que dificultan la corrección de los desequilibrios y el logro de cualquier convergencia en las sociedades y economías latinoamericanas.

Un factor fundamental es la escasa estabilidad y, en algunos casos, alta volatilidad en los ciclos de crecimiento económico latinoamericano. Los estudios sobre convergencia en estos países identifican una estrecha relación entre inestabilidad macroeconómica y el aumento de las disparidades territoriales. Estos estudios también señalan que los diferentes territorios 'subnacionales' latinoamericanos tienden a operar como conglomerados heterogéneos, con diferentes estados estacionarios y con dificultades de integración social, económica y territorial. La existencia de barreras a la integración y de una diversidad de regímenes económicos entre territorios podría estar en la base de la debilidad de los procesos de convergencia y de la inestabilidad económica latinoamericana, además de explicar la persistencia de la pobreza en los territorios más desfavorecidos (CUERVO, 2003).

Debemos también considerar que los procesos de apertura y de liberalización han tenido un impacto considerable en la producción y los niveles de vida de la población en las zonas rurales, aumentando los diferenciales con las áreas ur- 
banas. Téngase en cuenta que en los países latinoamericanos la primacía de los núcleos urbanos frente a otras áreas, en términos de concentración demográfica, económica y como centros políticos, es inusualmente alta en comparación con Estados Unidos y la Unión Europea. La elevada concentración demográfica en las zonas urbanas afecta de manera significativa a las posibilidades de crecimiento económico y de estabilidad institucional en otras áreas. Esta concentración económica y demográfica urbana y las posibilidades de crecimiento en otras regiones también se ve condicionada por la distribución territorial de las oportunidades de educación y de formación, por las condiciones y calidad de los servicios sociales y por la infraestructura disponible (HENDERSON, 2000; Cuervo, 2003).

Desde esta perspectiva estructural, la corrección de los desequilibrios podría acometerse parcialmente desde los acuerdos de integración porque las principales áreas de pobreza suelen estar en los países económicamente más grandes e influyentes (Argentina y Brasil en el MERCOSUR o Colombia en la CAN). Ello lo convierte sobre todo en un problema interno $y$, en menor medida, un tema supranacional, cuestión reversible parcialmente en la medida que se genere una visión de competitividad sistémica a escala sudamericana que se proponga mejorar las condiciones para una mayor equidad subnacional (FILIPPO, 2006).

\subsection{Valoración de las perspectivas ruralistas latinoamericanas}

Consideramos que no cabe hablar propiamente de corrientes únicas, sino de aproximaciones confluyentes desde diferentes disciplinas que enriquecen una 'visión latinoamericana' del desarrollo en las zonas rurales.

La perspectiva de la 'nueva ruralidad', en nuestra opinión, enfatiza la visión social e institucional. Propone una 'agenda de investigación' de los procesos del mundo rural desde una visión multidisciplinar, que mejora la comprensión de la complejidad del mundo rural latinoamericano (RAMOS y DeLGADO, 2005). Su principal mérito radica en haber captado los procesos de transformación relativamente recientes en las zonas rurales y percatarse de su significado y las oportunidades que ofrecen (KAY, 2005). Se supera una caracterización dicotómica de las estructuras agrarias (latifundio vs. minifundio, grandes empresarios orientados al mercado vs. pequeños agricultores que producen para el autoconsumo) y se evidencia la creciente multi- o pluriactividad en la economía campesina, el peso creciente del empleo y los ingresos rurales no agrícolas, la valoración del espacio rural (por ecologismo, recreación, turismo rural) y los cambios culturales y en estilos de vida de la población rural por la mayor interacción rural-urbana, la influencia 
de emigrantes retornados y los medios de comunicación. Su principal carencia es la multiplicidad de objetivos, algunos de ellos contradictorios y la ausencia de propuestas de políticas (KAY, 2005). La consideramos una aproximación germinal, establece principios y pautas para interpretar una realidad cambiante, priorizando el posicionamiento de los actores ante estas tendencias de cambio.

La perspectiva del 'desarrollo territorial rural' atiende, sobre todo, a una visión economicista e institucional de los cambios rurales. Bajo nuestro criterio, se apoya en la senda abierta desde la perspectiva anterior para interpretar esos cambios. Elabora un marco teórico propio y es más certera al plantear los vectores fundamentales de un enfoque territorial en las zonas rurales. Es una visión más integradora de la realidad rural con su entorno y con astucia capta la relevancia de las relaciones urbano-rurales para impulsar los procesos de transformación económica en las zonas rurales. Muy acertadamente llama la atención sobre los patrones de consumo y las demandas urbanas (sean indistintamente locales, regionales, nacionales o internacionales) como motor del cambio económico rural, aspecto fundamental en el proceso de cambio rural europeo. En las otras dos perspectivas latinoamericanas, las relaciones urbano-rurales se contemplan, sobre todo, desde la lógica del cambio social y cultural, soslayando la relevancia para la transformación económica. Un aspecto fundamental (para el diagnóstico y la elaboración de políticas) es la propuesta de tipologías de zonas rurales conjugando las transformaciones productiva e institucional. Esta propuesta únicamente adolece de una escasa operativización de la 'compleja arquitectura institucional' que propone para las intervenciones. No obstante, en nuestra opinión, el 'desarrollo territorial rural' es, teórica y operativamente, la aproximación más elaborada.

Por último, la perspectiva del 'enfoque territorial del desarrollo rural' representa la aproximación agrarista e institucional. Supone una maduración considerable de la propuesta inicial del IICA, aunque se mantiene en el terreno de áreas estratégicas y operativas sustanciales para la intervención. Su vía de entrada al territorio sigue siendo eminentemente agraria y evidencia una mayor atención a la seguridad alimentaria y una definición del territorio a partir de los recursos naturales base, preocupaciones secundarias en las perspectivas previas. Un avance importante es la contextualización de la visión territorial del desarrollo rural en el marco de la cohesión social y territorial. Consideramos como debilidades la visión excesivamente economicista de la competitividad territorial, obviando aspectos de la competitividad social o ambiental, presentes en la interpretación europea de 
este concepto que inspira la propuesta del $\| \mathrm{CA}^{36}$. A la vista de las condiciones existentes en el campo latinoamericano, algunas propuestas resultan avanzadas y probablemente sea más pertinente interpretarlas en términos de 'máximos', en cuyo caso sería recomendable contemplar alguna referencia a la gradualidad o enfatizar las carencias aún existentes ${ }^{37}$. En otros aspectos observamos cierta confusión de prioridades ${ }^{38}$.

En las tres perspectivas percibimos una influencia del enfoque LEADER y de la interpretación ex post de los alcances de esa iniciativa, más que de la experiencia global de política europea para las zonas rurales. La afinidad encontrada con multitud de iniciativas participativas y ascendentes en municipios y comunidades rurales en América Latina desde hace décadas podría ser una de las razones para explicar el atractivo de LEADER, por otro lado, iniciativa deudora de las experiencias en países en desarrollo (KORF y OUGHTON, 2006). Pero sería erróneo eludir el carácter de complementariedad de la iniciativa frente a la ingente inversión 'descendente' para la mejora de equipamientos sociales en las zonas rurales, amén del apoyo mantenido a las rentas agrarias. Las perspectivas latinoamericanas apenas atienden este hecho, manteniendo enfoques 'ascendentes y participativos' también para priorizar inversiones en infraestructuras y necesidades básicas. Creemos que hay múltiples cuestiones que exceden la competencia y capacidad de los agentes locales y ampliar la escala de intervención para realizar estas mejoras, es tan importante como superar la visión dicotómica y agrarista del mundo rural. Echamos en falta una referencia más decidida a los principios de cohesión social y económica (únicamente presente en la perspectiva del 'enfoque territorial') que contemple este tipo de inversiones, no tanto en términos de carencias del territorio, como de corrección de los desequilibrios entre territorios.

\footnotetext{
${ }^{36}$ Véase a este respecto, los aportes de Farrel et al. (1999) y Canto Fresno (2000).

${ }^{37}$ La indicación de impulsar un "desplazamiento de competencias - del ámbito nacional al nivel local y regional - a fin de fortalecer un nuevo orden territorial" (SEPúlveDA et al., 2003: 86) y de considerar que "las comunidades, empresarios y autoridades son los agentes idóneos para gestionar las políticas territoriales" (p.88) creemos que exceden considerablemente el alcance del enfoque territorial, así como las competencias y capacidades territoriales en buena parte del campo latinoamericano.
}

${ }^{38}$ Una "política de desarrollo rural que no tenga la capacidad de coordinar las políticas macroeconómicas con las políticas sectoriales es, sencillamente, ineficiente y costosa" (SEPÚlvEDA et al., 2003: 88). 


\section{A modo de conclusión: condicionantes para implementar un enfoque territorial en zonas rurales centroamericanas}

Para concluir nos referiremos a algunos aspectos que consideramos fundamentales precisar para valorar la implementación de un enfoque territorial en las zonas rurales centroamericanas. Distinguiremos entre condicionantes exógenos y endógenos al territorio, e incluiremos algunas consideraciones referentes al método de implementación en programas con este enfoque.

\section{I. Condicionantes exógenos a los territorios rurales}

Nos ceñimos específicamente a dos aspectos: la visión del desarrollo de las zonas rurales desde una perspectiva de 'cohesión social y económica' y la demanda externa al territorio como motor de transformación productiva.

\section{a. La cohesión social y económica como principio de intervención pública}

El énfasis en la gestión descentralizada de los programas e iniciativas locales o en la creación de un organismo territorial para la gestión del desarrollo económico en absoluto deberían percibirse como argumentos para atenuar la responsabilidad de la administración pública central en las zonas rurales. Bien al contrario, la administración central mantiene la responsabilidad de garantizar un entorno macroeconómico estable y una política económica que no opere en contra del medio rural, del sector agrario o de la seguridad alimentaria en estas áreas. Insistimos también en la responsabilidad por dotar de infraestructuras y equipamientos desde una lógica descendente y una visión más amplia del espacio que la resultante de las prioridades y necesidades particulares de cada territorio, considerando aquellos núcleos que pueden optimizar la cobertura de servicios públicos y la accesibilidad a un mayor número de territorios ${ }^{39}$.

Posicionar a las zonas rurales como áreas que pueden aportar a la competitividad y al crecimiento sostenido requiere su incorporación a ejes de producción e intercam-

\footnotetext{
${ }^{39}$ A este respecto véase la experiencia de la Estrategia de Microregiones y de los Centros Proveedores de Servicios en México. La atención a las carencias en infraestructuras y servicios básicos se apoyó en la identificación de aquellos núcleos de población, en la jerarquía de asentamientos, que aseguraban un mayor impacto de la inversión pública en función de la cercanía con otros núcleos de población menores.
} 
bio más dinámicos (FERRANTI et al., 2005). Corregir los desequilibrios territoriales se convierte pues en una condición imprescindible para generar crecimiento económico de forma estable en Centroamérica, en el ámbito nacional o supranacional.

Nuevos avances en la integración centroamericana, pero también en los esfuerzos nacionales por avanzar en la liberalización económica, podrían verse deslegitimados si la población no percibe las mejoras que ofrece la integración para su nivel de vida y si no se amortiguan los perjuicios que acarrearían para los territorios en condiciones más desfavorables. Téngase en cuenta que la primera gran reforma de fondos estructurales en la UE se planteó para corregir los desequilibrios entre regiones comunitarias, pero también para amortiguar el impacto negativo que el Mercado Único podría implicar en las regiones más desfavorecidas.

\section{b. La demanda externa como motor de transformación productiva}

Los vínculos con las zonas urbanas se concretan no sólo en el acceso a recursos ausentes en los territorios para la transformación estructural. También para establecer cauces de acceso a demandas que podrían encauzar la orientación productiva de esa transformación. El impacto de esta cuestión en el cambio rural europeo ha sido enorme.

El planteamiento de cambio en el apoyo a la agricultura europea se provoca cuando cada vez es más difusa la separación entre sociedad rural y urbana, al extenderse un sistema de valores que ha generalizado pautas comunes de consumo entre todos los grupos sociales. El avance de 'valores postmaterialistas' se produce cuando buena parte de la población ya no se preocupa por la satisfacción de necesidades materiales, como la alimentación - satisfecha en términos de cantidad - sino por aspectos situados en la calidad de vida, como el medio ambiente (MOYANO, 1997: 9-10). La experiencia europea evidencia cambios en las demandas de una sociedad que ha superado la precariedad en el consumo.

Sin embargo, esto no deja de ser una ilusión cuando se observan las realidades en los países centroamericanos. La inducción de cambios en los gustos y preferencias sociales en una población que continúa percibiendo el campo y lo rural como una cuestión atrasada, donde incluso la propia población rural no quiere permanecer ahí al carecer de las condiciones mínimas para vivir, puede aparecer como una cuestión irrelevante. Ni las condiciones reales facilitan ese cambio, ni los gobiernos tienen esa visión, ni existe la posibilidad de priorizarlo en sociedades donde existe un estado de precariedad permanente y los modelos de consumo -tanto en clases 
urbanas como rurales- aspiran a mejoras cuantitativas más que cualitativas. Hasta cierto punto, esto puede ser comprensible para una mayoría de la población que carece de las condiciones mínimas para vivir o ha visto empeorada su situación en los últimos años. Esta situación se ve agravada cuando incluso entre los estratos más pudientes de las sociedad -al fin y al cabo, los referentes de consumo más cercanos y visibles-, los modelos de consumo ostentosos refuerzan ese sesgo hacia la cantidad frente a la calidad, cuando no, directamente son asimilados y son aspiración entre los estratos menos pudientes.

Esta cuestión del consumo puede plantear varios dilemas: $\dot{e}$ es aceptable que se trate de inducir patrones de consumo más 'cualitativos' y ecológicamente responsables en estratos sociales con una profunda precariedad en sus medios de vida?; $\dot{\partial}^{\text {es }}$ criticable la aspiración a mejoras materiales cuantitativas y sustanciales, no ya en poblaciones con serias dificultades para sobrevivir, sino en estratos sociales


exportable el modelo de consumo responsable y cualitativo de una parte reducida de la población de nuestros países?; ¿ qué tiene más relevancia en el desarrollo de nuestras sociedades: el avance de esos modelos de consumo -hasta cierto punto alternativos- o la posibilidad de elegir?

No pretendemos dar respuesta a estas cuestiones. Pero consideramos que resultan de suficiente peso como para asumir que los cambios de mentalidad y de las demandas sobre bienes rurales pueden convertirse en un obstáculo considerable para que estos patrones de consumo actúen como motor de la transformación productiva rural.

\subsection{Condicionantes endógenos de los territorios rurales}

La superación del aislamiento en un territorio rural necesita de agentes locales que interaccionen con agentes externos. La endogeneización de las demandas externas requiere acceso a la información y a los recursos necesarios. La facilidad para esa inserción en el entorno se verá influida por los canales, recursos y espacios inducidos desde fuera, pero también por la existencia de condiciones territoriales que lo faciliten.

\section{a. Sobre la transformación institucional}

El 'enfoque territorial' representa, en primera instancia, una transformación institucional del territorio rural. En Centroamérica, los cambios institucionales resultado 
de los procesos de descentralización afianzan un nuevo escenario para los agentes. Siendo procesos aún inconclusos, estos cambios proveen las bases para afianzar una autonomía político-administrativa propia en unidades territoriales menores y para un cambio en la gobernanza territorial. Hasta ahora se ha favorecido el desarrollo social local (aspectos de educación primaria, salud, suministro de agua, infraestructura local) y todavía persisten carencias en términos de descentralización fiscal y de capacidad para el endeudamiento a los gobiernos locales. La instauración de mecanismos democráticos de consulta, rendición de cuentas y transparencia en la toma de decisiones públicas y el fortalecimiento de la sociedad civil organizada se espera que deriven en una mayor presión y exigencia al desempeño sobre los gobiernos locales (FINOT, 2001 y 2003). La necesidad de coordinación y colaboración entre agentes públicos, privados y sociales a diferentes niveles debe servir como germen de nuevos mecanismos de gobernanza territorial.

Sin embargo, la necesidad de actuar colectivamente y desarrollar alianzas puede enfrentarse a profundos recelos entre agentes locales, evidencia de profundas brechas sociales y desigualdades, o bien de un Estado deslegitimado históricamente y capturado por las élites (muy especialmente, en el nivel local) que no ofrece seguridad ni mecanismos de garantía para respaldar los acuerdos. Piénsese que esta nueva gobernanza territorial también plantea la ruptura de una identidad local muy arraigada en la figura del 'notable local' como pieza mediadora y articuladora de las relaciones entre el Estado central y las administraciones locales (AROCENA, 1995).

\section{b. Sobre la transformación económica}

Pero además, esta transformación institucional no se traduce en una transformación productiva de manera automática. A modo indicativo, la profundización o ampliación de la implicación en la cadena productiva se puede enfrentar a la falta de mercados de bienes o servicios (proveedores, clientes, información, tecnología, infraestructuras, demanda final); la diversificación de las actividades económicas puede enfrentarse a un fuerte arraigo al monocultivo; $y$ el aprovechamiento de los recursos locales requiere observar bajo otra perspectiva unos vínculos tradicionales y unos recursos que siempre han estado 'ahí', entre otros aspectos. Cuando hablamos de 'condiciones endógenas' también nos referimos a la existencia de una dotación mínima de recursos naturales con potencial de revalorización, centros urbanos intermedios vertebradores del territorio, un tejido mínimo de organizaciones sociales y productivas, el acceso al mercado crediticio, a recursos financieros y políticas e instrumentos públicos de fomento para inversiones productivas. Como 
señala Sumpsi (2006), el enfoque territorial no elimina la necesidad de políticas sectoriales sino que la hace más evidente.

\subsection{Consideraciones de método}

Para finalizar haremos unas consideraciones de método, matizando algunas apreciaciones hechas en los apartados anteriores que afectan directamente a la operativización del 'enfoque territorial'.

\section{a. Definición de lo urbano-rural}

Dejando a un lado las discusiones sobre lo rural que han precedido a numerosas reflexiones sobre el desarrollo rural en los últimos años ${ }^{40}$, existe una diferencia de aplicación fundamental, y probablemente de percepción, en las perspectivas europea y centroamericana. En la discusión europea, la dificultad para definir qué es lo rural está relacionada con una concepción del espacio rural en base a tres componentes: una ecológica, una social (económica y ocupacional) y una mental (o cultural) ${ }^{41}$. En la terminología de los organismos internacionales y de los ministerios nacionales, se conciben como 'zonas rurales' el conjunto de comunidades y asentamientos humanos fuera del núcleo principal (o urbano) y dispersas en un término municipal, con independencia del tamaño de estos asentamientos y limitado a la componente de localización residencial y la distancia desde las ciudades ${ }^{42}$.

\section{b. Consideraciones en torno a la dinamización y la participación}

Con anterioridad a la iniciativa LEADER en algunos países europeos no existían iniciativas participativas o de desarrollo endógeno (España, Portugal, Irlanda, Grecia). La experiencia LEADER tuvo un evidente impacto como acción innova-

\footnotetext{
${ }^{40}$ A modo indicativo, Baigorri (1995), Marsden (1995) y Carpio Martín (2000).

${ }^{41}$ Para Sancho Hazak (1997), esta concepción deriva en el intento de asignar pautas sociales a espacios físicos, lo que origina la dificultad para llegar a un consenso sobre qué es lo rural.

${ }^{42}$ Para Ferranti et al. (2005: 31) existen, al menos, tres formas de describir la 'economía rural' (sic): un enfoque sectorial, un enfoque de ingresos para los hogares $y$ un enfoque territorial, que examina el espacio rural más generalmente, en términos de densidad de población y de distancia desde las ciudades.
} 
dora. En América Central, desde hace al menos dos décadas, hay un bagaje amplísimo de experiencias comunitarias y de desarrollo endógeno y una densa red de organizaciones de desarrollo que promueven la participación comunitaria a menor escala.

En un contexto así, un programa con las características del 'enfoque territorial' deja de resultar tan innovador y debe enfrentarse a una memoria histórica y a un know-how con frecuencia maleado. Garantizar un funcionamiento democrático y una representatividad efectiva, elementos esenciales, puede enfrentarse a dificultades considerables para (re)generar expectativas y dinamizar los agentes locales por la fácil asimilación a experiencias pasadas más o menos exitosas. También existe el riesgo de profundizar aún más una 'cultura de la subsidiariedad' que con frecuencia se critica duramente en la labor de las organizaciones no gubernamentales de desarrollo. En el ámbito de la participación ciudadana, a menudo valorada como indicador del compromiso por una iniciativa determinada, suelen obviarse aspectos como las expectativas por los beneficios inmediatos para los participantes (en especial, cuando las decisiones políticas tienen una alta relevancia en las sociedades) o el 'coste de oportunidad' para desarrollar otras actividades más productivas, cuando las decisiones políticas pierden progresivamente relevancia. Creemos que todo ello son retos a considerar para establecer una gobernanza territorial adecuada.

\section{c. Arquitectura institucional}

Un último aspecto sobre el que llamamos la atención es la arquitectura institucional necesaria para gestionar los programas y los fondos de apoyo a las iniciativas endógenas. La experiencia centroamericana al respecto presenta algunas particularidades que suele sesgar la percepción sobre la experiencia europea. El referente más conocido son los órganos gestores de programas de desarrollo con personalidad jurídica propia y cierta autonomía administrativa frente a los institutos a los que se adscriben los programas. Esto les concede una flexibilidad de ejecución considerable, aunque también facilita que sean objeto de proselitismo político. La adscripción a niveles superiores de gobierno (como órganos de presidencia o vicepresidencia) suele brindar más agilidad, por otro lado, a costa de una sostenibilidad que no suele exceder el período de gobierno (BERDEGUÉ et al., 2003). La arquitectura institucional propuesta es diferente por completo a estas experiencias.

La gestación de la estructura de planificación y gestión debe surgir de los propios agentes locales quienes deben dotarla de la normativa y los modos de gobernanza 
que consideren oportuna. Esto no impide asesoramiento externo, pero las decisiones finales recaen por completo en los actores locales. En la operativa, la mayor preocupación que comparten los enfoques europeos y centroamericanos es la capacidad de articulación horizontal y la generación del consenso desde la base. Escasa atención suele darse a la capacidad de 'agencia' (agency) o de articulación vertical, por otro lado aspecto clave para conseguir la inserción en redes y espacios de toma de decisiones en ámbitos externos al territorio (KAY, 2005).

Una última cuestión es el alcance de las competencias y responsabilidades de estos organismos gestores del desarrollo rural. Las experiencias más avanzadas de estructuras asentadas en los territorios europeos han comenzado a plantear la asunción de nuevas competencias, al menos como entes coordinadores de políticas sectoriales en el territorio (ESPARCIA et al., 2000). En el caso de las experiencias centroamericanas, frente a algunas propuestas que proponen dotar a estas estructuras de competencias para proveer bienes públicos territoriales o regionales (SEPÚlVEDA et al., 2005), consideramos más conveniente descartar cualquier discusión al respecto. Amén de la considerable carga que supondría para estas estructuras y los recelos que pueden generarse en los organismos públicos competentes, podría amenazar la consolidación de unos procesos de descentralización aún incipientes.

\section{Bibliografía}

ALADI-CAN - MERCOSUR - OTCA - CEPAL - CAF (2005), "Un nuevo tratamiento de las asimetrías en la integración sudamericana", Documento de Conclusiones del Foro de Reflexión 'Un nuevo tratamiento de las asimetrías en la integración sudamericana", 21 de octubre de 2005. La Paz: Secretaría General de la Asociación Latinoamericana de Integración (ALADI).

ALADI (2005), Informe del Secretario General sobre la evolución del proceso de integración durante el año 2005. Montevideo: Asociación Latinoamericana para la Integración (ALADI).

AmAdor Hidalgo, F.; Sumpsi ViñAs, J. M. y Romero Rodríguez, J. J. (2005), “Un intento de valoración de las acciones de DR en América Latina. El proyecto EXPIDER", ponencia presentada en el VII Encuentro de la Sociedad de Economía Mundial (Área 2: Desarrollo económico y desarrollo sostenible) 21 al 23 de abril. Madrid: Sociedad de Economía Mundial. 
Ambrosio AlbalÁ, M. (2007), Elementos institucionales en las zonas rurales: una propuesta metodológica para su identificación y valoración en comarcas de Andalucía y Nicaragua, Tesis doctoral. Directores: Prof. Dr. Francisco Amador Hidalgo y Prof. Dr. José Juan Romero Rodríguez. Córdoba: Universidad de Córdoba - Departamento de Gestión Empresarial y Métodos Cuantitativos.

Arocena, J. (1995), El desarrollo local. Un desafío contemporáneo. Caracas: Centro Latinoamericano de Economía Humana (CLAEH) - Universidad Católica del Uruguay - Editorial Nueva Sociedad.

BaIGoRrl, A. (1995), "De lo rural a lo urbano", Ponencia presentada en el V Congreso Español de Sociología, Granada.

BANCO MUNDIAL (1997), Rural development: from vision to action. Washington DC: Banco Mundial.

BANCO MUNDIAL (2003), Reaching the rural poor. Washington DC: Banco Mundial.

Bandeira, P.; I. AtANCE y J. M. Sumpsi (2004), "Las políticas de desarrollo rural en América Latina: requirimientos de un nuevo enfoque", Cuadernos de Desarrollo Rural, 51, 115-136.

BecatinI, G. y E. Rullani (1993), "Sistema locale e mercato globale", Economia e Politica industriale, 80.

Berdegué, J.; A. Schetman, G. Escobar; E. Ramírez y J. C. Caro (2003), Análisis de la situación de las dinámicas sociales, las políticas sociales y las innovaciones requeridas para el ámbito rural, documento elaborado para la Fundación Chile 21. Santiago de Chile: RIMISP.

BID (2003), Perfil de Estrategia de Desarrollo Rural, diciembre. Washington DC: Departamento de Desarrollo Sostenible - Banco Interamericano de Desarrollo (BID).

BID (2005), Estrategia de Desarrollo Rural, borrador, 22 de febrero. Washington DC: Unidad de Desarrollo Rural - Departamento de Desarrollo Sostenible - Banco Interamericano de Desarrollo (BID).

BIEKART, K. (2005), Políticas de las ONGs europeas para América Latina: tendencias y perspectivas recientes, documento de trabajo. Utrecht: Organización 
Intereclesiástica para la Cooperación al Desarrollo (ICCO) - Instituto de Estudios Sociales (ISS).

Caldentey del Pozo, P. (2004), La integración centroamericana frente al reto institucional. Documento de trabajo del proyecto 'La integración centroamericana: beneficios y costos'. San Salvador y México: SICA-CEPAL.

CAN - Comunidad Andina de Naciones (2004), Conclusiones del Diálogo Presidencial Andino sobre Integración, Desarrollo y Cohesión Social, 7 de diciembre de 2004, Cuzco.

CAN - COMUNIDAD ANDINA dE NACIONES (2006), Tratamiento de las asimetrías en la Comunidad Andina, Documento de trabajo, SG/dt349, 4 de julio. Lima: Secretaría General de la Comunidad Andina de Naciones.

Canto Fresno, C. (2000), "Nuevos conceptos y nuevos indicadores de competitividad territorial para las áreas rurales", Anales de Geografía de la Universidad Complutense, 20, 69-84.

Carpio Martín, J. (2000), "Desarrollo local para un nuevo desarrollo rural", Anales de Geografía de la Universidad Complutense, 20, 85-100.

CCAAM-Consejo Consultivo Andino de Autoridades Municipales (2005), Declaración de la Primera Reunión del Consejo Consultivo Andino de Autoridades Municipales (CCAAM) el 1 de julio de 2005. Lima.

CEPAL-UE (2004), Conferencia "Integración económica y cohesión social. Lecciones aprendidas y perspectivas", 11 y 12 de noviembre. Ciudad de México: Comisión Económica para América Latina y el Caribe (CEPAL) - Unión Europea (UE).

Comisión de las Comunidades Europeas (2002), Comunicación de la Comisión 'La lucha contra la pobreza rural-Política y enfoque comunitarios respecto al desarrollo rural y la gestión sostenible de los recursos naturales en los países en desarrollo', COM(2002) 429 final. Luxemburgo: Oficina de las Publicaciones Oficiales de las Comunidades Europeas.

COMISIÓN EUROPEA (2005), Una asociación reforzada entre la Unión Europea y América Latina: Comunicación de la Comisión al Consejo y al Parlamento Europeo, COM (2005) 636 final. Luxemburgo: Oficina de Publicaciones Oficiales de las Comunidades Europeas. 
Consejo del Mercado Común (2003), Decisión MERCOSUR/CMC/DEC Nº 27/03: Fondos Estructurales, XXV Reunión del Consejo del Mercado Común del 15/XII/03, Montevideo.

Consejo del Mercado Común (2004), Decisión MERCOSUR/CMC/DEC N 45/04: Fondo para la Convergencia Estructural del Mercosur, XXVII Reunión del Consejo del Mercado Común del 16/XII/04, Belo Horizonte.

CONSEjo del MerCAdo COMún (2005a), Decisión MERCOSUR/CMC/DECNº 18/05: Integración y funcionamiento del Fondo para la Convergencia Estructural y fortalecimiento de la estructura institucional del Mercosur, XXVIII Reunión del Consejo del Mercado Común del 19/VI/05, Asunción.

Consejo del MerCado Común (2005b), Decisión MERCOSUR/CMC/DECN²4/05: Reglamento del Fondo para la Convergencia Estructural delMercosur, XXIX Reunión del Consejo del Mercado Común del 08/XII/05, Montevideo.

CSN-Comunidad Sudamericana de Naciones (2005), Declaración sobre la Comunidad Sudamericana de Naciones, Primera Cumbre de la Comunidad Sudamericana de Naciones, celebrada el 29 y 30 de septiembre de 2005, Brasilia.

CSN - Comunidad SudAmericANA de NACIONES (2006), Declaración de Cochabamba: Colocando la Piedra Fundamental para una Unión Sudamericana, Segunda Cumbre de la Comunidad Sudamericana de Naciones, celebrada el 8 y 9 de diciembre de 2006, Cochabamba.

Cuervo, L.M. (2003) “Evolución reciente de las disparidades económicas territoriales en América Latina: estado del arte, recomendaciones de política y perspectivas de investigación", Serie Gestión pública, 41, noviembre. Santiago de Chile: Dirección de Gestión del Desarrollo Local y Regional - Instituto Latinoamericano y del Caribe de Planificación Económica y Social (ILPES).

Dahl-Ostergatrd, T.; D. Moore, V. Ramirez, M. Wenner y A. Bonde (2003), "Community-Driven Rural Development. What have we learned?" , Technical Papers Series, RUR-1 12. Washington DC: Sustainable DevelopmentDepartment-Inter-American Development Bank (IADB).

Delgado, M. M. (2004), La política rural europea en la encrucijada, Serie Estudios, 155. Madrid: Ministerio de Agricultura, Pesca y Alimentación. 
DGD - Dirección General De Desarrollo (2000), EC Policy and approach to rural development. Fighting rural poverty, 15 de junio. Bruselas: Comisión de las Comunidades Europeas.

DGRE - Dirección General de Relaciones Exteriores (2006), Conferencia de Alto Nivel "Promover la cohesión social: las experiencias de la Unión Europea y de América Latina y el Caribe", 27 y 28 de marzo en Viena. Bruselas: Comisión Europea - Dirección General de Relaciones Exteriores (DGRE).

EChEVERRI, R. y E. MosCardi (2005), Construyendo el desarrollo rural sustentable en los territorios de México. México: Instituto Interamericano de Cooperación para la Agricultura (IICA).

ECHEVERRI, R. y M. P. Ribero (2002), Nueva ruralidad. Visión del territorio en América Latina y el Caribe. San José: Instituto Interamericano de Cooperación para la Agricultura (IICA).

EuIS, F. y S. BIGGS, (2001), "Evolving themes in rural development 1950s-2000s", Development Policy Review, 19(4), 437-448.

Esparcia, J.; J. Noguera y M. D. Pitarch (2000), "LEADER en España: desarrollo rural, poder, legitimación, aprendizaje y nuevas estructuras", Documents $d$ Anàlisi Geogràfica de la Universidad Autónoma de Barcelona, 37, 95-113.

ESPON (2005), Final report of ESPON Project 2.1.3: The territorial impact of CAP and rural development policy, European Spatial Planning Observatory Network (ESPON). Aberdeen: Arkleton Institute for Rural Development Research.

Farrell, G.; S. ThiRION y P. Soto (1999), "La competitividad territorial. Construir una estrategia de desarrollo territorial con base en la experiencia de LEADER", Innovación en el medio rural, Cuaderno ${ }^{\circ} 6$, diciembre. Bruselas: Observatorio Europeo LEADER.

Ferranti, D. De; G. E. Perry, W. Foster, D. Lederman y A. Valdés (2005), Beyond the city: the rural contribution to development. Washington DC: Banco Mundial.

FILPPO, A. DI (2006), Las asimetrías en los acuerdos de integracón de América Latina y el Caribe, SP/Di N ${ }^{\circ} 5-06$, junio. Caracas: Sistema Económico Latinoamericano y del Caribe (SELA). 
FINOT, I. (2001), Descentralización y participación en América Latina: una mirada desde la economía, Boletín del ILPES, 9, LC/IP/L. 195. Santiago de Chile: Instituto Latinoamericano y del Caribe de Planificación Económica y Social (ILPES).

FINOT, I. (2003), Descentralización en América Latina: cómo hacer viable el desarrollo local, Serie Gestión Pública, 38. Santiago de Chile: Instituto Latinoamericano y del Caribe de Planificación Económica y Social (ILPES).

Garrido, F.; J. A. Gómez Limón; E. Vera Toscano y E. Moyano (2006), "Actitudes y percepciones sobre la multifuncionalidad agraria: el caso de Andalucía", ponencia presentada en el VI Coloquio Ibérico de Estudios Rurales, 23 y 24 de febrero. La Rábida, Huelva: Asociación Española de Economía Agraria-Sociedad Portuguesa de Estudios Rurales.

Giarracca, N. (comp.) (2001), ¿Una nueva ruralidad para América Latina?, Colección Grupos de Trabajo. Buenos Aires: Consejo Latinoamericano de Ciencias Sociales (CLACSO).

Giordano, P.; M. Moreira y F. QueVedo (2004), "El tratamiento de las asimetrías en los acuerdos de integración regional", Documento de Divulgación, 26. Buenos Aires: Instituto para la Integración de América Latina y el Caribe (INTAL).

Henderson, V. (2000), "How Urban Concentration Affects Economic Growth" , Policy Research Working Papers, 2326. Washington DC: Banco Mundial.

IICA (2000), "El desarrollo rural sostenible en el marco de una nueva lectura de la ruralidad. Nueva ruralidad", Serie Documentos Conceptuales, marzo. Panamá: Instituto Interamericano de Cooperación para la Agricultura (IICA) - Centro Interdisciplinario de Investigaciones sobre Desarrollo (CIDER).

Janvry, A. De y E. Sadoulet (2004), "Hacia un enfoque territorial del desarrollo rural", Cuarto Foro Temático Regional de América Latina y el Caribe 'Cosechando Oportunidades: Desarrollo Rural en el Siglo XXI', 19 a 21 de octubre. San José: Banco Mundial.

JOUEN, M. (1999) "La aportación de LEADER. Panorama de la diversidad nacional", Seminario 'Integrar las enseñanzas de LEADER en las políticas rurales', junio. Valencia: Observatorio Europeo LEADER.

KAY, C. (2005), "Enfoques sobre el desarrollo rural en América Latina y Europa desde mediados del siglo veinte", Seminario Internacional 'Enfoques y Perspectivas 
de la Enseñanza del Desarrollo Rural', 31 de agosto al 2 de septiembre. Colombia: Universidad Javeriana.

Korf, B. y E. OUGHTON (2006), "Rethinking the European countryside - can we learn from the South?", Journal of Rural Studies, 22, 278-289.

KrUgman, P. (1995), Development, Geography and Economic Theory. Boston: The MIT Press.

MAILAT, D. (1995), "Territorial dynamic, innovative milieus and regional policy", Entrepeneurship and Regional Development, 7.

MARSDEN, T. (1995), "Beyond agriculture? Regulating the New Rural Spaces", Journal of Rural Studies, 11 (3), 285-296.

Miranda, B. (2003), Capital social, institucionalidad y territorios: el caso de Centroamérica. San José: Instituto Interamericano para la Cooperación Agrícola (IICA) - Servicio de Información Mesoamericano sobre Agricultura Sostenible (SIMAS).

Moscoso, D. J. (2005), "Las representaciones sociales de la agricultura en Andalucía: rumbo hacia la 'itinerancia' ", Acciones e Investigaciones Sociales, 21, 35-273.

Moyano, E. (1997), "Presentación", en: Grupo De Brujas, Por un cambio necesario en la agricultura europea, 9-11. Madrid: Ministerio de Agricultura, Pesca y Alimentación.

NORTH, D. C. (1993), Instituciones, cambio institucional y desempeño económico, $2^{a}$ reimpresión. México: Fondo de Cultura Económica.

OCDE (2002), The future of rural policy. From sectoral to place-based policies in rural areas. Paris: Paris: Organización para la Cooperación y el Desarrollo Económico (OCDE).

OCDE (2006a), The new rural paradigm: policies and governance. Paris: Organización para la Cooperación y el Desarrollo Económico (OCDE).

OCDE (2006b), "Reinventing rural policy", OECD Policy Brief, octubre. Paris: Organización para la Cooperación y el Desarrollo Económico (OCDE).

OtTONE, E. (dir.) (2007), Cohesión social. Inclusión y sentido de pertenencia en América Latina y el Caribe, LC/G.2335. Santiago de Chile: Comisión Económica 
para América Latina y el Caribe (CEPAL) - Agencia Española de Cooperación Internacional (AECI).

Pérez Correa, E. (2001), "Hacia una nueva visión de la ruralidad", en: Giarracca, op.cit., 17-29.

Pérez Correa, E. (2002), "Lo rural y la nueva ruralidad", en: Pérez Correa y Sumpsi, op.cit., 15-32.

Pérez Correa, E. y J. M. Sumpsi (coord.) (2002), Políticas, instrumentos y experiencias de desarrollo rural en América Latina y Europa. Madrid: Ministerio de Agricultura, Pesca y Alimentación.

Pérez Correa, E. y M. A. Farah (comp.) (2004), Desarrollo rural y nueva ruralidad en América Latina y la Unión Europea. Bogotá: Universidad Pontificia Javeriana - Centre de coopération internationale en recherche agronomique pour le développement (CIRAD).

Pérez Haro, E. (2003), "La participación social como instrumento de desarrollo rural: el Programa de Zonas Marginadas de México", en: Pérez, E. y J. M. SuMPSI, op.cit., 213-237.

Pérez, A. y Caballero, J. M. (2003), La nueva ruralidad en Europa y su interés para América Latina. Programa Cooperativo FAO-Banco Mundial (FAO/CP). Roma: Organización de las Naciones Unidas para la Agricultura y la Alimentación (FAO).

Phong, D. T.; F. Amador y J. J. Romero (2007), Bases for Territory-based Rural Development in Vietnam. Hanoi: Agencia Española de Cooperación Internacional (AECI) - Ayuda, Intercambio y Desarrollo (AIDA) - ETEA.

Porter, M. E. (1998), "Clusters and the new economics of competition", Harvard Business Review, noviembre-diciembre, 77-90.

Ramos, E. y Delgado, M. M. (2005), "El enfoque territorial del desarrollo rural: de las aportaciones teóricas a su aplicación en Andalucía", en: DeLGADO, M.; M.C. López y J.J. ROMERo (coords.), Economía y territorio. La Comunidad Autónoma Andaluza, Colección ETEA. Bilbao: Editorial Desclée de Brouwer.

RICHARDS, M. (2004), Hacia un mayor entendimiento de la pobreza rural en América Central: lecciones de la literatura sobre el desarrollo rural. San José: Departamento 
para el Desarrollo Internacional del Gobierno del Reino Unido (DfiD) - Unidad Regional de Asistencia Técnica (RUTA) - Overseas Development Institute (ODI).

ROdRíGuez, R. (2000), "El desarrollo rural en Iberoamérica desde una óptica eurocéntrica", Seminario Internacional La nueva ruralidad en América Latina, 22 al 24 de agosto. Bogotá: Pontificia Universidad Javeriana - Facultad de Estudios Ambientales y Rurales.

RojAs RUEDA, M. E. (2002), "Alianzas productivas como instrumento de desarrollo rural en Colombia", en: Pérez CorreA, E. y J.M. Sumpsi (coord.), op.cit., 185-212.

Romero, J. J. y G. FerRero (ed.) (2004), Desarrollo rural en Nicaragua. Del consenso en los principios a una propuesta para la acción. Bilbao: Editorial Desclée de Brouwer.

RUIz, A. (2002), "El concepto de territorialidad propuesto en la Ley de Desarrollo Rural Sustentable", Ponencia presentada en el Seminario Internacional Enfoque Territorial del Desarrollo Rural, octubre. Veracruz (Méjico): Secretaría de Agricultura, Ganadería, Desarrollo Rural, Pesca y Alimentación (SAGARPA).

SANCHO HAZAK, R. (1997), "Estructura demográfica y tipificación de los asentamientos y áreas rurales españolas", en: Gómez Benito y GonzÁlez RodríGuez (ed.), Agricultura y sociedad en la España contemporánea, 173-224. Madrid: Centro de Investigaciones Sociológicas (CIS) - Ministerio de Agricultura, Pesca y Alimentación.

SaRACENO, E. (2003), "La política europea de desarrollo rural y su utilidad en el contexto latinoamericano", en: PÉREZ, E. y J. M. SUMPSI, op.cit., 169-181.

Schejtman, A. y J. Berdegué (2003), Desarrollo rural territorial. Santiago de Chile: Centro Latinoamericano para el Desarrollo Rural (RIMISP).

Schmit, H. B. y E. M. Benasayag (2006), "De la experiencia europea a la realidad en los países en vías de desarrollo: una propuesta para la comparación de acciones del Programa LEADER con inicativas brasileñas de desarrollo local en el medio rural", Estudios Geográficos, LXVII (260), 169-198.

Sepúlveda, S.; A. Rodríguez y M. Portilla (2003), El enfoque territorial del desarrollo rural. San José: Instituto Interamericano de Cooperación para la Agricultura (IICA). 
SICA - Sistema de Integración Centroamericano (2006a), Declaración de la XXVIII Reunión Ordinaria de Jefes de Estado y de Gobierno de los países del SICA, 11 de julio de 2006. Panamá: Sistema de Integración Centroaméricana (SICA).

SICA - Sistema de Integración Centroamericano (2006b), Declaración de la XXIX Reunión Ordinaria de Jefes de Estado y de Gobierno de los países del SICA, 16 de diciembre de 2006. San José: Sistema de Integración Centroaméricana (SICA).

StOKER, G. (1998), "Governance as theory: five propositions", International Social Science Journal, 50 (155), 17-28.

SUMPSI, J. M. (2006), "Relaciones entre las transformaciones institucionales y productivas en el marco del desarrollo territorial rural", Seminario Internacional "Territorios rurales en movimiento". 23 al 26 de abril. Santiago de Chile: RIMISP - IDRC.

SumpsI, J. M. (2006b), Experiencias piloto de desarrollo local rural en América Latina: lecciones del proyecto EXPIDER en Bolivia, Ecuador y Honduras, RUR-06-02. Washington DC: Departamento de Desarrollo Sostenible - Banco Interamericano de Desarrollo (BID).

UE-BID (2003), Seminario "Social Cohesion in the EU-Latin America-Caribbean strategic partnership", 5 y 6 de junio, Bruselas.

URIOSTE, M. y L. BaLDOMAR (1999), "Participación popular, descentralización y Ley de Tierras: políticas diferenciadas para el Desarrollo Rural en Bolivia", Seminario Latinoamericano 'Heterogeneidad agraria y políticas diferenciadas', 27 a 29 de noviembre. Cocoyoc (Méjico): FAO - RIMISP.

VARGAS, R. (1999), "El Programa de Desarrollo Integral Campesino - PDIC - del Fondo DRI", Experiencias exitosas de Combate a la Pobreza rural en América Latina: Lecciones para una reorientación de las políticas. Santiago de Chile: FAO - RIMISP.

VEIGA, J. E. (2001), "Brasil rural precisa uma Estratégia de Desenvolvimento", Serie Textos para Discussão, 1. Brasilia: Convenio Federación Instituto de Pesquisas Económicas (FIPE) - Instituto Interamericano para la Cooperación en la Agricultura (IICA). 